\title{
Effects of reinforcement history for following rules on sensitivity to contingencies of reinforcement
}

\author{
Carolina Aguilera \\ West Virginia University
}

Follow this and additional works at: https://researchrepository.wvu.edu/etd

\section{Recommended Citation}

Aguilera, Carolina, "Effects of reinforcement history for following rules on sensitivity to contingencies of reinforcement" (2000). Graduate Theses, Dissertations, and Problem Reports. 799.

https://researchrepository.wvu.edu/etd/799

This Thesis is protected by copyright and/or related rights. It has been brought to you by the The Research Repository @ WVU with permission from the rights-holder(s). You are free to use this Thesis in any way that is permitted by the copyright and related rights legislation that applies to your use. For other uses you must obtain permission from the rights-holder(s) directly, unless additional rights are indicated by a Creative Commons license in the record and/ or on the work itself. This Thesis has been accepted for inclusion in WVU Graduate Theses, Dissertations, and Problem Reports collection by an authorized administrator of The Research Repository @ WVU. For more information, please contact researchrepository@mail.wvu.edu. 


\title{
Effects of Reinforcement History for Following Rules on Sensitivity to Contingencies of Reinforcement
}

\author{
Carolina Aguilera
}

\author{
Thesis submitted to the \\ Eberly College of Arts and Sciences \\ at West Virginia University \\ in partial fulfillment of the requirements \\ for the degree of
}

\author{
Master of Arts \\ in \\ Psychology
}

Philip N. Chase, Ph.D., Chair

Stanley H. Cohen, Ph.D.

Kennon A. Lattal, Ph.D.

Department of Psychology

Keywords: rule-governance, instructions, sensitivity, history effects, rule-governed behavior Morgantown, West Virginia 2000 


\section{ABSTRACT \\ Effects of Reinforcement History for Following Rules on Sensitivity to Contingencies of Reinforcement}

\section{Carolina Aguilera}

The present experiment manipulated subjects' experimental history of reinforcement for following rules in order to assess sensitivity to contingency changes. Ten undergraduate students were presented with four training tasks. Half the subjects were presented with instructions that corresponded with the reinforcement contingencies for these tasks (Accurate Instructions group), while the other half was presented with instructions that did not correspond with the reinforcement contingencies (Inaccurate Instructions group). After meeting stability criteria, unsignaled changes in the contingencies of one of the tasks were made to test for sensitivity. Although the behavior of all the subjects eventually changed after contacting the changed contingencies, results suggest that the behavior of the inaccurately instructed subjects was more likely to contact the differential availability of points during testing. These data lend support to the notion that subjects' history of reinforcement with rules affects sensitivity. Nonetheless, it is not clear whether sensitivity to the differential availability of points required subjects' initial history of responding to correspond with the responding that led to reinforcement during testing. Directions for future research are suggested. 


\section{Acknowledgments}

I would first like to thank my advisor and committee chair Phil Chase for being a constant source of support. His continuous guidance, enthusiasm and his ability to strike the perfect balance between providing direction and encouraging independence makes him an incredible advisor and teacher. I am also indebted to Andy Lattal. His guidance and insightful comments have been very much appreciated. Vous êtes un excellent professeur Andy! I would also like to thank Stan Cohen for the many useful comments he made to this thesis.

Thanks are also due to my research assistants Chad Taylor, Heather Stucky, and Chris Ferro. Thank you guys for all your help! I would also like to thank Brady Reynolds for his love, understanding and encouragement when it was most required.

I am indebted to my father for showing me what it is to be passionate about one's work. Finalmente, quiero agraderle a mi madre Maria Eugenia por todo el amor y comprensión que me ha dado siempre. Gracias mami por todos tus sacrificios, por apoyarme durante todas las etapas de mi vida, y por ser una mujer a la cual yo admiro muchísimo. Te adoro mami. 
Table of Contents

Title Page $\ldots \ldots \ldots \ldots \ldots \ldots \ldots \ldots \ldots \ldots \ldots \ldots \ldots \ldots \ldots \ldots \ldots \ldots \ldots \ldots \ldots \ldots$

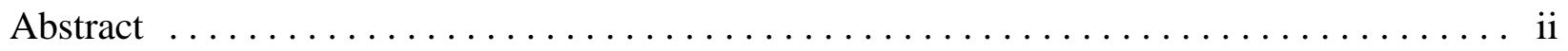

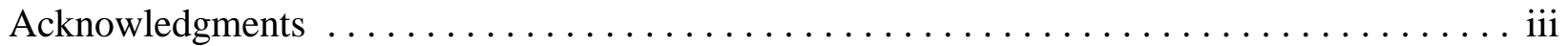

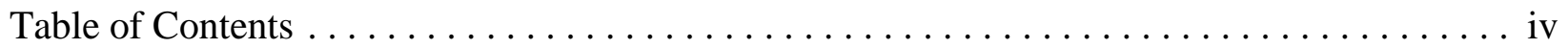

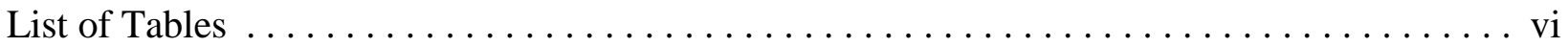

List of Figures $\ldots \ldots \ldots \ldots \ldots \ldots \ldots \ldots \ldots \ldots \ldots \ldots \ldots \ldots \ldots \ldots \ldots \ldots \ldots \ldots$

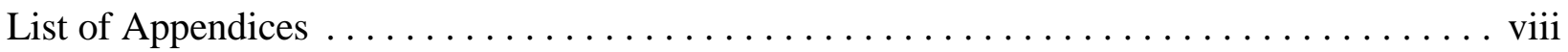

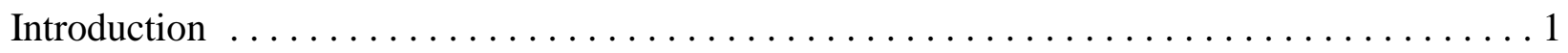

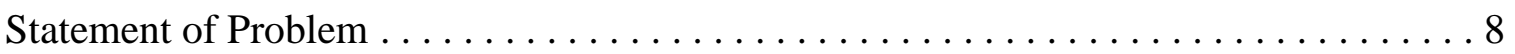

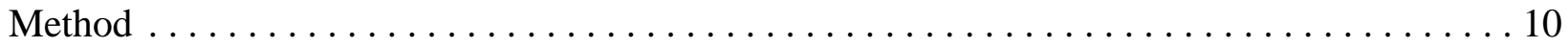

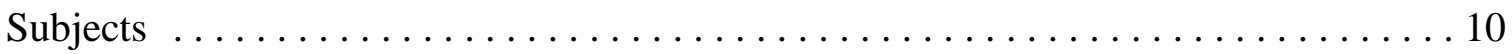

Apparatus . . . . . . . . . . . . . . . . . . . . . 10

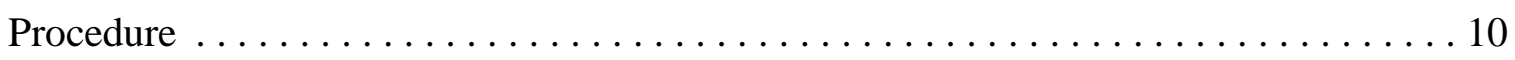

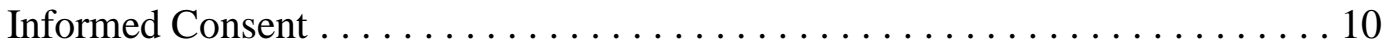

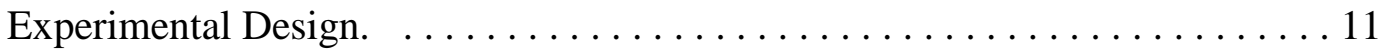

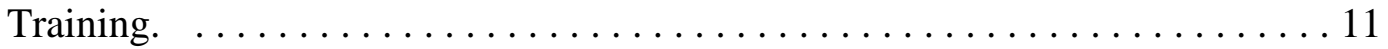

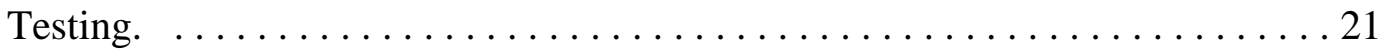

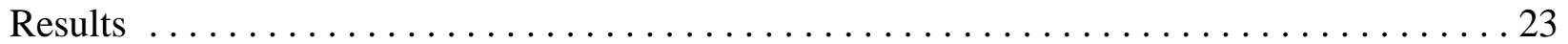

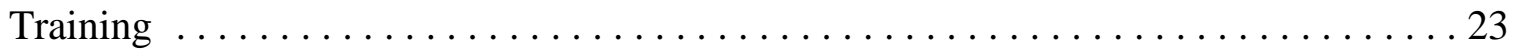

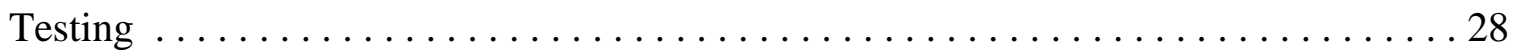


Points Earned . . . . . . . . . . . . . . . . . . . . . . . . . . . . . 29

Representative Subjects. . . . . . . . . . . . . . . . . . . 29

Outlier Subjects. ...................... 31

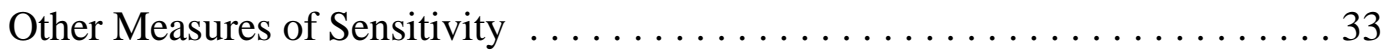

Schedule Effects Between Training and Mixed DRL Conditions. . . . . 33

Schedule Effects Between Mixed DRL and Limited Hold Conditions . . 37

Schedule Effects Between Limited Hold and Cost Conditions. . . . . . . 37

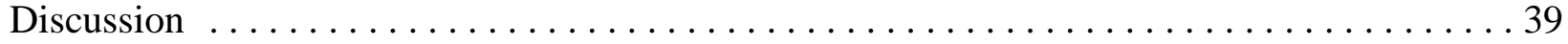

Differences Between Groups $\ldots \ldots \ldots \ldots \ldots \ldots \ldots \ldots \ldots \ldots \ldots \ldots \ldots \ldots \ldots \ldots \ldots \ldots \ldots \ldots$

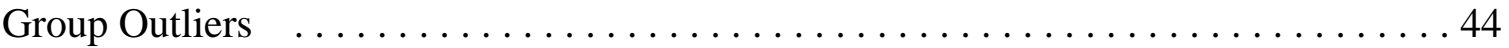

Differences Between Conditions: Training to Mixed DRL Testing $\ldots \ldots \ldots \ldots \ldots 4$

Differences During Limited Hold and Cost Conditions $\ldots \ldots \ldots \ldots \ldots \ldots$

Future Research . . . . . . . . . . . . . . . . . . . . . . . . . 49

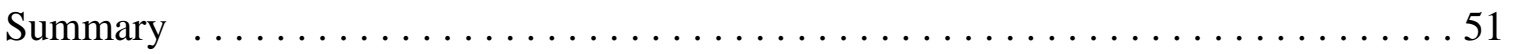

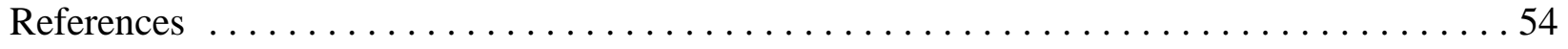

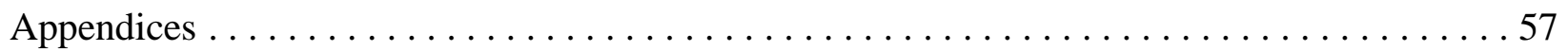




\section{List of Tables}

Table 1. Order of task presentations during the first training session $\ldots \ldots \ldots \ldots \ldots$

Table 2. Order of task presentations during the first testing session $\ldots \ldots \ldots \ldots \ldots \ldots 22$

Table 3. Number of training blocks of trials, money earned, and average amount of money

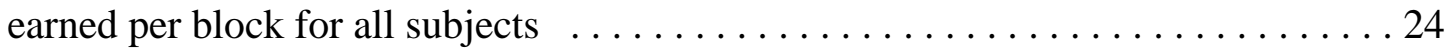




\section{List of Figures}

Figure 1. Screen presented to Accurately Instructed subjects during the "Roulette" game. . . 15

Figure 2. Screen presented to Accurately Instructed subjects during the "Dragging" game. . 16

Figure 3. Screen presented to Accurately Instructed subjects during the "Letters" game. . . 18

Figure 4. Screen presented to Accurate Instructions subjects during "Button" game. . . . . . 20

Figure 5. Training accuracy across all tasks for representative subjects. $\ldots \ldots \ldots \ldots$

Figure 6. Average interresponse times during training for representative subjects. . . . . . 27

Figure 7. Points earned across conditions for representative subjects. . . . . . . . . 30

Figure 8. Points earned across conditions for outlier subjects. . . . . . . . . . . . 32

Figure 9. Interresponse times distributions in 2-s bins across training and Mixed DRL

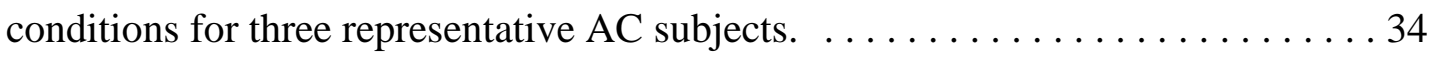

Figure 10. Interresponse times distributions in 2-s bins across training and Mixed DRL conditions for two representative IN subjects. $\ldots \ldots \ldots \ldots \ldots \ldots \ldots \ldots$

Figure 11. Interresponse times distributions in 2-s bins across Mixed DRL and Limited Hold conditions for two representative subjects. $\ldots \ldots \ldots \ldots \ldots \ldots \ldots \ldots \ldots$

Figure 12. Interresponse times distributions in 2-s bins across Limited Hold and Cost conditions for two representative subjects. 


\section{List of Appendices}

Appendix A. Informed Consent Form approved by the Institutional Review Board . . . . 57

Appendix B. Instructions read by the experimenter during the first training block . . . . . 59

Appendix C. Training accuracy across all tasks for Subjects AC 2, AC 3, and AC $4 \ldots \ldots 1$

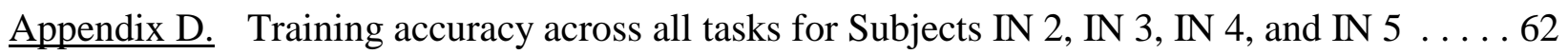

Appendix E. Points earned across conditions for Subjects AC 2, AC 3, and AC 4. . . . . . 63

Appendix F. Points earned across conditions for Subjects IN 4 and IN 3 . . . . . . . . 64 
Effects of Reinforcement History for Following Rules

on Sensitivity to Contingencies of Reinforcement

Behavior analysts have distinguished between behavior acquired through direct exposure to environmental contingencies (contingency-governed behavior) and behavior acquired through the verbal specification of environmental contingencies (rule-governed behavior). Skinner (1969) suggested that behavior controlled by a contingency-specifying stimulus is inherently different from behavior acquired through exposure to contingencies. In the three decades since Skinner's initial description of these phenomena, numerous studies have investigated the factors involved in establishing and, subsequently, maintaining behavior acquired through the presentation of written or vocal instructions, or through the demonstration of the target response.

Because it has been argued that one of the defining characteristics of rule-governed behavior is its insensitivity to changes in the environment (e.g., Shimoff \& Catania, 1998; Shimoff, Catania, \& Matthews, 1981), understanding the variables that affect the sensitivity of rule-governed behavior to changes in experimental contingencies has been of special interest to scientists studying rule-governance. Tests for sensitivity usually assess whether experimental manipulations affect behavior in an orderly and replicable manner (Madden, Chase, \& Joyce, 1998) or whether responding is appropriate according to some experimenter's defined definition (e.g., Shimoff et al., 1981).

Most researchers concerned with studying sensitivity have found it useful to create experimental situations where verbal antecedents and contingencies are pitted against each other (Shimoff \& Catania, 1998). For example, a subject may be told to press a button 40 times to receive points, although a fixed interval (FI) 10-s schedule of reinforcement has been 
programmed to deliver reinforcers. This kind of contrast between instructions and contingencies of reinforcement has been essential to test clearly the relation between rules or instructions and contingencies of reinforcement. If the pattern of responding specified by the instructions is different from that expected if the contingency requirement were to be met, assessing whether the instructions or the experimental contingencies are maintaining the target behavior is possible.

Using methods that contrast control by contingencies of reinforcement and control by instructions, experimenters have isolated some of the variables that affect sensitivity to the contingencies of reinforcement. For example, Galizio (1979) contrasted instructions to respond on avoidance schedules of reinforcement with contingencies that either did not require an avoidance response or required an avoidance response different from that specified in the instructions. Galizio examined if contact with the changed contingencies controlled whether instructed behavior would come under the control of said contingencies. It was concluded that if changes in the contingencies were present, but the new contingencies did not preclude reinforcement for responding to the old contingencies, the probability that a subject's behavior would contact these changes decreased.

The second experiment in Galizio (1979) tested this hypothesis directly. In the first phase, instructional control was established and maintained under a four-component multiple-schedule where three components had response-loss intervals of 10,30, and 60-s, and one component had no monetary loss. Subjects were presented with an accurate instruction along with each component. Once behavior matched the set contingencies, a "No Contact" condition was introduced where the loss programmer was turned off, but the instructions and their corresponding stimuli still signaled the multiple schedule. In spite of the withdrawal of the 
avoidance contingency, the subjects continued to exhibit avoidance behavior as instructed in the first phase. After the "No Contact" condition, a "Contact" condition was introduced. Although the same sequence of lights and labels as in the previous condition was presented, each of the four components changed to an avoidance schedule with a response-loss interval of 10 -s. Under this condition there was an immediate breakdown of instructional control. Rate of responding increased for all the subjects to the level previously associated with the 10-s response loss component. These results led Galizio to conclude that subjects' behavior had to contact changes in the contingencies before instructional control was lost.

Besides contact, other variables such as the amount of response variability present at the time of the contingency changes (Joyce \& Chase, 1990) and the variety of instructions used during training (LeFrancois, Chase, \& Joyce, 1988) all have been found to affect the sensitivity of rule-governed behavior to changing contingencies. The effect of subjects' history of reinforcement with rules also has received some attention as it relates to sensitivity. For example, in the second experiment of Hayes, Brownstein, Zettle, Rosenfarb, and Korn (1986), responding was reinforced on a multiple differential-reinforcement-of-low-rates (DRL) 6-s fixed ratio (FR) 18 schedule of reinforcement with these two components randomly alternating every 2-min. Subjects were told to respond rapidly in the presence of the green light and to push slowly when the red light was lit. Subjects then were divided into two groups. One group had a light signaling which schedule was in effect during all three sessions while the other group had the light lit during only the first session. These two groups then were subdivided further: some received only the "Go Slow" red light, some the "Go Fast" green light, and others received both sets of instructions with their corresponding lights alternating every 1-min. 
Results show that the rate of responding of at least two of the five subjects who were presented with instructions during all three sessions and who received both sets of instructions increased and decreased systematically with the changes in the schedules, but these subjects only earned points under the instructed schedule. These results suggested to Hayes et al. (1986) that the subjects' behavior had contacted the inaccuracy of the instructions, but contact did not weaken rule-governance. Hayes et al. hypothesized that this insensitivity may have been due to subjects having had a long history of reinforcement for following rules. They suggested that perhaps behavior that has had a long history of reinforcement may not be modified by the consequences encountered during a brief experiment.

Another study that attempted to examine the relation between histories of reinforcement for rule-following and sensitivity to contingency changes was conducted by Wulfert, Greenway, Farkas, Hayes, and Dougher (1994). In their first experiment, 24 subjects who had scored high or low on a questionnaire of self-reported rigidity were presented with a task similar to the one used by Hayes et al. (1986). During the first two sessions, points could be earned on a multiple DRL 4-s FR 18 schedule of reinforcement where the components alternated every 2-min. Half the high and low scoring subjects were presented with instructions that accurately described the initial schedules of reinforcement. The rest of the subjects were presented with minimal instructions that only specified that reinforcers could be earned by pressing a button. During the last session, an unsignaled change in the contingencies was presented so that extinction was in effect although the lights that had been previously associated with the multiple schedule components continued to alternate. 
The results from the Wulfert et al. (1994) study showed that the subjects who had obtained a high score on the rigidity questionnaire were more likely to continue responding in the absence of reinforcement than the subjects who had obtained a low score on the questionnaire. These results were used to support the notion that subjects with a history of reinforcement for rule-following were more likely to follow a previously adopted response even under extinction. One aspect of the Hayes et al. (1986) and Wulfert et al. (1994) studies that preclude supporting the conclusions postulated by these researchers is that subjects' histories of reinforcement for rule-following were not manipulated directly. It may be possible, however, that directly manipulating subjects' histories of reinforcement for following rules might increase or decrease the chances of behavior being sensitive to the changing contingencies.

Ruckstuhl (1996) conducted a series of experiments that attempted to manipulate subjects' experimental history with rule-following. Ruckstuhl postulated that differential histories of reinforcement for rule-following would lead to differential sensitivity to changing contingencies. Four experiments were conducted. Subjects were provided with accurate contingency-specifying instructions in the presence of a yellow stimulus that were positively correlated with an FR and a DRL schedule of reinforcement. Subjects were also provided with inaccurate instructions in the presence of a blue stimulus that did not specify whether the FR or DRL schedule was in effect. During testing, the scheduled contingencies changed for the subjects who followed the instructions in the presence of the yellow stimulus and who did not follow the instructions in the presence of the blue stimulus. Although both blue and yellow stimuli continued to be presented, the schedules of reinforcement changed. Reinforcers during testing could be obtained on a mixed low-rate differential-reinforcement-of-high-rate (DRH) schedule 
(Experiment 1), an FI schedule (Experiments 2 and 3), or an FI followed by a DRL schedule (Experiment 4). Ruckstuhl examined whether subjects' behavior was more sensitive to the changes in the presence of the blue stimulus than in the presence of the yellow stimulus. The results, however, were inconclusive as differences in history of reinforcement for following or not following rules led to systematic differences in sensitivity for only a few subjects.

Procedural problems were encountered that prevent a conclusive explanation of Ruckstuhl's results. The first problem with the Ruckstuhl (1996) study is that in three of four experiments he did not obtain discriminative control of instruction-following. Thus, the training histories did not result in rule-following under one stimulus condition and not following rules under the other stimulus condition. Ruckstuhl suggested that the long pre-experimental histories of the subjects for following rules made such discriminative control difficult to obtain. Second, while trying to build an experimental history, Ruckstuhl trained his subjects with a history of responding under an FI and a DRL schedule of reinforcement. Although this provided a minimal variety of conditions under which not following rules was reinforced, perhaps training should have included a training on more experimental tasks if the experiment needed to override subjects' extensive pre-experimental history of reinforcement for rule-following. Third, Ruckstuhl did not use schedules during his testing phases that have been shown previously to be successful in distinguishing between instructed behavior that is sensitive or insensitive to changes in contingencies (e.g., Lamons \& Chase, 1992).

Lamons and Chase (1992) investigated the conditions under which instructed behavior exhibits differential sensitivity to different schedules of reinforcement. Three kinds of contingency changes were investigated. Subjects were assigned randomly to one of three 
experimental conditions and each subject was exposed to four phases. Each session began with instructions indicating that subjects were to wait 10-s before pressing a button labeled "EARN." The first three phases were the same for all subjects. Responding during the first phase was reinforced on a DRL 10-s schedule of reinforcement. The second phase consisted of changing to a DRL 4-s schedule and the third phase reversed back to the DRL 10-s schedule. In the final phase of the experiment, one group was exposed to a mixed DRL 10-s DRL 4-s schedule (Mixed DRL), the second group was exposed to a mixed DRL 10-s DRL 4-s Limited Hold 4-s schedule (Limited Hold) and the third group was exposed to a mixed DRL 10-s DRL 4-s Limited Hold 4-s with a point loss contingency (Cost).

The mixed schedules in the last phase were selected to provide three different kinds of contingencies. In the first half of the Mixed DRL schedule, responses with an interresponse time (IRT) $\geq 10$-s were reinforced. In the second half of the Mixed DRL schedule, responses with an IRT $\geq 4$-s were reinforced. Therefore, this condition was named "No Contact" because insensitivity to the changed contingencies did not alter the rate of reinforcement and, because the schedules were mixed, there were no changes in antecedent stimuli between schedule presentations. This contingency change was similar to the "No Contact" condition used by Galizio (1979) and by Shimoff et al. (1981).

In the second half of the Limited Hold schedule used in the Lamons and Chase (1992) study, responses with an IRT $\geq 4$-s and $\leq 8$-s were reinforced. This condition was called "Extinction Contact" because during 50\% of the sessions, responding in the same manner as under the DRL 10-s schedule was not reinforced. This was similar to the procedure used by Hayes et al. (1986) where responding during $50 \%$ of the trials was placed under extinction. In the 
second half of the Cost schedule, responses with an IRT $\geq 4$-s and $\leq 8$-s were reinforced, while responses with an IRT < 4-s or $>8$-s resulted in the deduction of one point. This condition was dubbed "Point Loss Contact" because insensitivity to the changed contingencies resulted in the loss of points. Thus, the "Point Loss Contact" condition was analogous to the "Contact" condition in Galizio (1979).

During the first three phases, all subjects followed the instructions. During the fourth phase, the behavior of the subjects in the "No Contact" condition did not show any sensitivity to the changes in the conditions, as could be expected from the results obtained from phase two. For the "Extinction Contact" group, two of the three subjects showed differences in responding during the different schedule components. Responding for all subjects during the "Point Loss Contact" condition changed during each schedule component. Thus, the behavior of the "No Contact" subjects was not sensitive to the contingencies, and the "Extinction Contact"condition was less likely than the "Point Loss Contact" condition to affect contingency sensitivity. In designing the current study, it was reasoned that using schedules like those utilized by Lamons and Chase (1992) would assist in detecting differential rule-following better than the schedules used by Ruckstuhl (1996).

\section{Statement of Problem}

The purpose of this experiment was to analyze whether histories of reinforcement for following or not following rules led to differential sensitivity to changes in schedules of reinforcement. Past research has provided inconclusive results. Although the manipulation of instructions has led to differential sensitivity for some subjects in some experiments, a direct test of whether this differential sensitivity is due to a reinforcement history of following or not 
following rules has not been conducted. Ruckstuhl (1996) attempted to do this, but, as discussed earlier, procedural problems were encountered with respect to (a) the inability to obtain discriminative control of instruction-following, (b) lack of variety in training, and (c) failure to use schedules used previously to investigate sensitivity to changes in schedules of reinforcement.

The current study attempted to avoid these problems. Because of the difficulties Ruckstuhl (1996) encountered while trying to obtain discriminative control of rule-following during training within a single-subject paradigm, two groups of subjects were used in the present experiment. The training phase provided one group of subjects with a history of reinforcement for rule-following through the presentation of accurate instructions. The second group was always presented with inaccurate instructions. Furthermore, in an attempt to build an experimental history of reinforcement that could override previous histories, a variety of tasks were used during the training phase. Four different computer games were presented. Accurately instructed subjects were provided with instructions that, when followed, led to the successful playing of the games. Inaccurately instructed subjects received instructions that, when followed, led to the unsuccessful playing of the games. Lastly, the three mixed schedules used in the Lamons and Chase (1992) study were used during testing. Lamons and Chase concluded that various levels of sensitivity were obtained with these mixed schedules. Because one goal of the present experiment was to analyze some of the variables that may affect the sensitivity of behavior to environmental changes, using schedules shown to produce various levels of sensitivity was warranted.

Results from the present study should help analyze a variable purported by Hayes et al. (1986) to affect sensitivity to experimental changes: a history of reinforcement for following 
rules. Thus, this study directly manipulated histories of reinforcement for following and not following rules and tested whether this historical manipulation led to differential sensitivity to changes in local contingencies. If sensitivity to schedule contingencies was affected by subjects' history of reinforcement for rule-following, then the behavior of subjects given a history of reinforcement for rule-following should have shown less sensitivity to schedule contingencies than the behavior of subjects given a history of reinforcement for not following rules.

\section{Method}

\section{$\underline{\text { Subjects }}$}

Fourteen female West Virginia University undergraduate students were assigned randomly to one of two experimental conditions. Students were paid for their performance in the experiment and for their attendance.

$\underline{\text { Apparatus }}$

Tasks and schedule contingencies were programmed in Microsoft Visual Basic (v.5) for Windows on an IBM-compatible, Pentium I $200 \mathrm{MHZ}$ computer. Sessions were conducted in a room measuring approximately 2 meters square. The work space consisted of a chair, a table, and a computer placed on the table. A 14-inch monitor was used to present information to the subjects. An IBM style 101-key keyboard and a Microsoft mouse were placed within the subjects' reach.

Procedure

Informed Consent. Each subject was required to read and sign a copy of an informed consent form approved by the West Virginia University Institutional Review Board (see Appendix A). 
Experimental Design. Sensitivity to the schedules of reinforcement was analyzed by manipulating two independent variables. Type of group was the between-subjects independent variable while type of mixed schedule of reinforcement was the within-subjects independent variable. Subjects in the Accurate Instructions (AC) group were presented with instructions that accurately described how to maximize point earnings on the four training tasks (described below). Following these instructions resulted in the earning of points. For the Inaccurate Instructions (IN) group, the instructions inaccurately described the training task requirements; following the instructions never resulted in the earning of points. During training, both groups were exposed to a series of tasks and, during testing, both groups were exposed to a series of three mixed schedules of reinforcement (also described below).

Training. Subjects who were wearing a watch were asked to give their watch to the experimenter for the length of the session. During the first session, all subjects were escorted into the experimental room where the experimenter read a set of general instructions (Appendix B). Any questions the subjects had were answered by repeating the relevant part of the instructions. The experimenter then left the room after asking the subject to read a set of general instructions on the screen. The general instructions were presented only during the first training block and were as follows:

(a) Welcome to the human behavior lab!

Get comfortable and when you are ready to read the general instructions, press the "CONTINUE" button.

(b) In order to earn points, you will get to play various games. Before you play a game, you will be presented with instructions. 
During all games, a beep will signal that you have earned a point. In order to have the point registered, press the "REGISTER" button.

After you have registered your points, you will hear another beep, a stack of coins will briefly appear on the screen and the point counter will increment. So, as soon as you have earned a point, register it!

Press the "CONTINUE" button to advance.

(c) Now you are ready to begin the session. Remember to earn and register your points. Each point will be worth three-quarters of a cent.

Press the "CONTINUE" button to begin the session.

Pressing the "Continue" button after the last general instruction was followed by a screen containing instructions on how to earn points in the first training task. Each subject participated in two blocks of tasks per daily session with a break of 5-min between blocks. Each training task was in effect for 6-min and every task was presented once per block. The order of presentation of the four tasks was quasi-random to prevent the presentation of the same initial task during two consecutive blocks (see Table 1 for the order of task presentations during the first training session for all subjects).

Reinforcers for all tasks were points. During each task, a .5-s beep signaled that a point had been earned. The next trial started only after the subject had pressed the "Register" button. Registering the points resulted in the presentation of another beep, the presentation of a picture of a stack of coins for .5-s and an increment of the point counter. The computer recorded the total number of points registered and the total number of trials presented for each task during each block. 
Table 1

Order of Task Presentations During the First Training Session

\begin{tabular}{|c|c|c|}
\hline Block & Task & Length \\
\hline 1 & $\begin{array}{l}\text { Roulette } \\
\text { Dragging } \\
\text { Button } \\
\text { Letters }\end{array}$ & $\begin{array}{l}\text { 6-min } \\
6-\min \\
6-\min \\
6-\min \end{array}$ \\
\hline & BREAK & 5-min \\
\hline 2 & $\begin{array}{l}\text { Button } \\
\text { Roulette } \\
\text { Dragging } \\
\text { Letters }\end{array}$ & $\begin{array}{l}\text { 6-min } \\
\text { 6-min } \\
\text { 6-min } \\
\text { 6-min }\end{array}$ \\
\hline
\end{tabular}


The first task, "Roulette," required the subject to press a button labeled "Spin" (Figure 1).

This displayed three random numbers between 0 and 9 on the screen. The AC group was

presented with the following instructions that accurately described the task:

1. If the first and the second numbers are the same, press the "FIRST" button.

2. If the first and the third numbers are the same, press the "SECOND" button.

3. If the second and the third numbers are the same, press the "THIRD" button.

4. If all the numbers are the same, press the three buttons once from left to right.

5. If all the numbers are different, press the three buttons once from right to left.

The IN group was presented with the following inaccurate instructions:

1. If the first and the third numbers are the same, press the "FIRST" button.

2. If the second and the third numbers are the same, press the "SECOND" button

3. If the first and the second numbers are the same, press the "THIRD" button.

4. If all the numbers are the same, press the three buttons once from right to left.

5. If all the numbers are different, press the three buttons once from left to right.

Incorrectly pressing one of the three buttons terminated the trial. Pressing the "SPIN" button

began a new trial and three new random numbers were presented.

The second task, "Dragging," required the subject to drag and drop objects into the icon of a trash can (Figure 2). There were three different groups of objects: clocks, drinks, and weapons.

The screen was either blue, yellow, or white, and the color of the screen for each trial was chosen at random by the computer. The screen's color determined which of the three groups of objects should be dragged and dropped into the trash can so that a point could be earned. The AC group received the following instructions that accurately described the task:

1. If the screen is blue, drag the CLOCKS into the trash can.

2. If the screen is yellow, drag the WEAPONS into the trash can.

3. If the screen is white, drag the DRINKS into the trash can. 

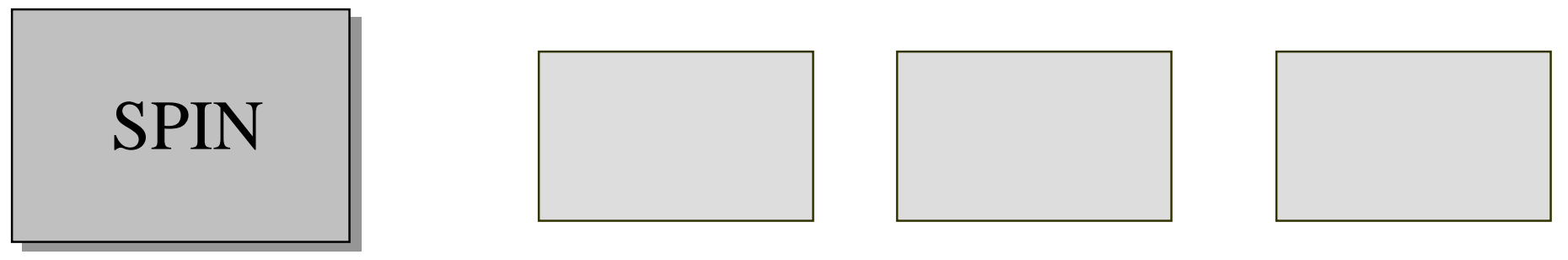

Points Earned: 0
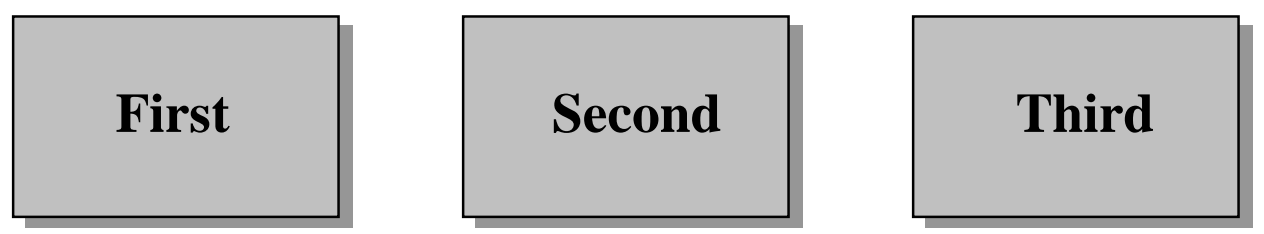

1. If the first and the second numbers are the same, press the "FIRST" button.

2. If the first and the third numbers are the same, press the "SECOND" button.

3. If the second and the third numbers are the same, press the "THIRD" button.

4. If all the numbers are the same, press the three buttons once from left to right.

5. If all the numbers are different, press the three buttons once from right to left.

That's all!!! If you press the incorrect button, try again by pressing the "SPIN" button. Don't forget to register your points by pressing on the "REGISTER" button after you hear a beep.

Figure 1. Screen presented to Accurately Instructed subjects during the "Roulette" game. 


\section{Points Earned: 0}

\section{REGISTER}

1. If the screen is blue, drag the CLOCKS into the trash can.

2. If the screen is yellow, drag the WEAPONS into the trash can.

3. If the screen is white, drag the DRINKS into the trash can.

After you put the objects into the trash can, drag the match that will appear on the screen into the trash can. If you hear a beep, you have put the objects into the trash can correctly. Don't forget to register your points by pressing the "REGISTER" button that will appear after you hear a beep.

Figure 2. Screen presented to Accurately Instructed subjects during the "Dragging" game. 
The IN group received the following inaccurate instructions:

1. If the screen is blue, drag the DRINKS into the trash can.

2. If the screen is yellow, drag the CLOCKS into the trash can.

3. If the screen is white, drag the WEAPONS into the trash can.

After dragging at least three icons into the trash can, the picture of a match appeared on the screen. Once the match was dragged into the trash can, a puff of smoke came out from the trash can. Dragging the incorrect objects into the trash terminated the trial. All trials began with the presentation of all 10 objects on the screen.

The third task, "Letters," involved presenting the subject with three random letters: an "A", a "B", or a "C" (see Figure 3). Each trial required the subject to change one, two, or all of the letters by pressing the buttons below each letter. Every time one of these three buttons was pressed, the computer changed the letter above the pressed button into an "A", a "B", or a "C" depending on the initial letter presented. If the letter to be changed was an "A", pressing the button below this letter changed the letter to a "B." If the letter was a "B", it changed into a "C" and if the letter was a "C", it changed into an "A." The AC subjects received the following instructions that accurately described the task:

1. If 2 or more of the letters are "A"s, then make all the letters "B"s. 2. If 2 or more of the letters are "B"s, then make all the letters "C"s. 3. If 2 or more of the letters are "C"s, then make all the letters "A"s. 4. If all the letters are different, then make all the letters like the one in the middle.

The IN subjects were presented with the following inaccurate instructions:

1. If 2 or more of the letters are "A"s, then make all the letters "C"s.

2. If 2 or more of the letters are "B"s, then make all the letters "A"s.

3. If 2 or more of the letters are "C"s, then make all the letters "B"s.

4. If all the letters are different, then make all the letters like the first letter. 

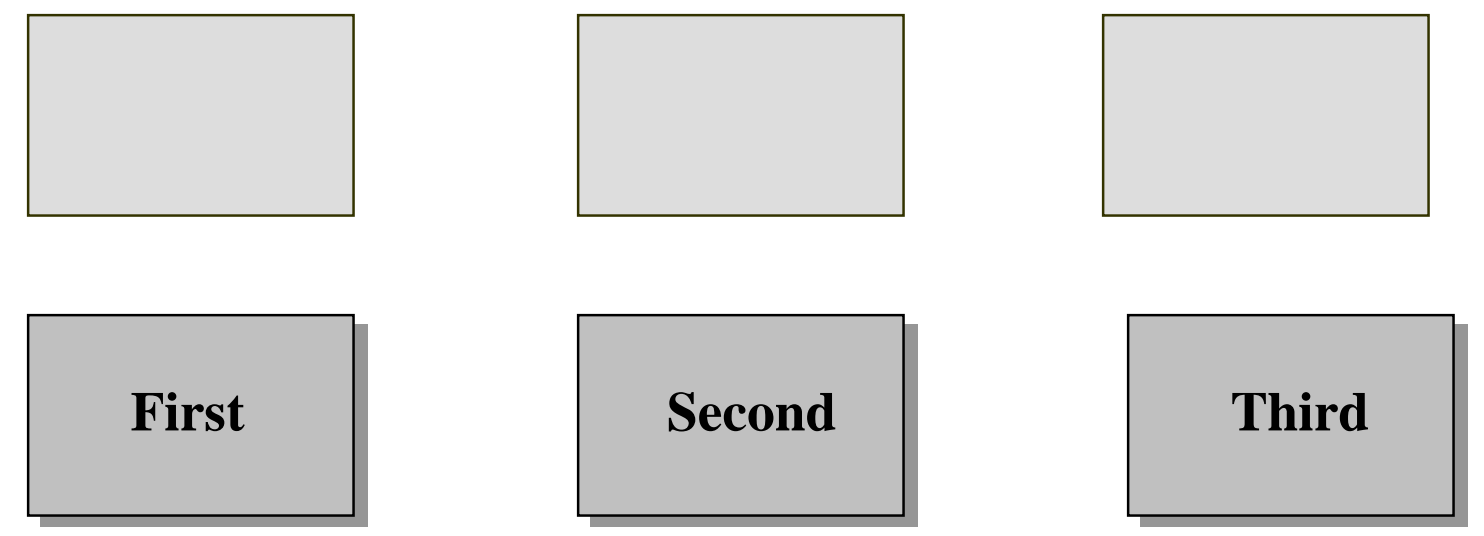

\section{Submit Changes}

\section{Points Earned: 0}

1. If 2 or more of the letters are "A"s, then make all the letters "B"s

2. If 2 or more of the letters are "B"s, then make all the letters "C"s

3. If 2 or more of the letters are "C"s, then make all the letters "A"s

4. If all the letters are different, then make all the letters like the one in the middle.

Once you are ready to submit your changes, press "Submit Changes". If you hear a beep, you changed the letters correctly. You must register your point by pressing "REGISTER" before you may continue with the game.

Figure 3. Screen presented to Accurately Instructed subjects during the "Letters" game. 
After making the changes, the subject had to press the button labeled "Submit Changes." Every time this button was pressed, a new trial was recorded. If the changes were not correct, a new trial started immediately. Three new letters were presented during the beginning of all trials.

The fourth task, "Button," required the subject to press a button labeled "Earn" that operated on a DRL 10-s schedule of reinforcement (Figure 4). If the subject waited $\geq 10$-s before pressing the "Earn" button, a point was earned. If the subject waited $<10$-s, the screen remained unchanged. The computer recorded IRTs and every button press resulted in the resetting of the IRT timer. The AC group was instructed accurately to, "wait 10 seconds before pressing the 'EARN' button.” The IN group, on the other hand, was instructed inaccurately to, "wait 2 seconds before pressing the 'EARN' button."

Stability and accuracy had to be achieved for each training task before testing began. Accuracy for the "Roulette," "Dragging," and "Letters" tasks was obtained by dividing the number of points registered in each task by the number of trials presented during each task. For the "Button" task, accuracy was assessed by dividing the number of IRTs $\geq 10$-s by the total number of IRTs emitted in that block. Stability was achieved once the following five criteria were met during the last three training blocks: (a) accuracy for all tasks was above $85 \%$ and there was no upward or downward trend in the data; (b) subject earned at least $\$ 2.00$ per block; (c) no IRTs $<8$-s on the "Button" task were present; (d) rate of responding for the "Button" task did not show an upward or downward trend and the average rate of responding for each of the last three training blocks was within $10 \%$ of the mean rate of responding of the last three training blocks; and (e) visual inspection of the IRTs distributions showed little response variability. Once these criteria were met, the testing phase of the experiment began. 


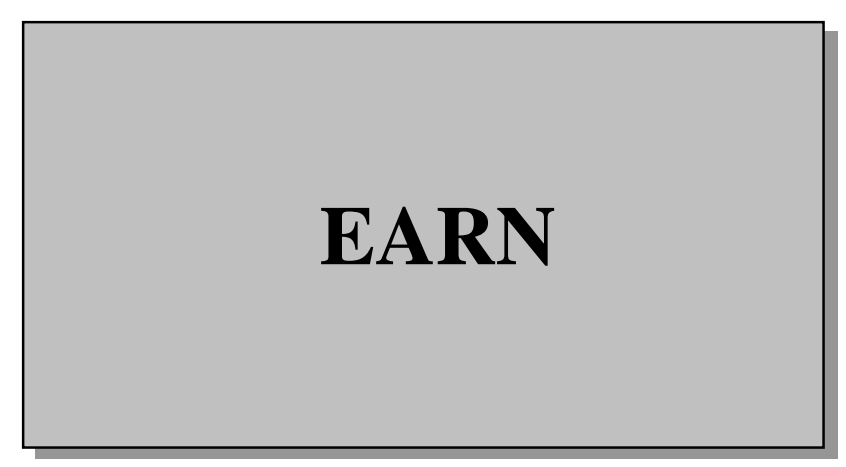

Points Earned: 0

Wait 10 seconds before pressing the "EARN" button. You will hear a beep when you have earned a point. In order to register the point, press the "REGISTER" button that will appear on the screen.

Figure 4. Screen presented to Accurate Instructions subjects during "Button" game. 
Testing. During the testing stage, the subjects were presented with Tasks 1 through 3 as described above. The "Button" task, however, was changed. Although the screen and the instructions were the same, the contingencies differed in that one of three mixed schedules was presented. The first schedule was a mixed DRL 10-s DRL 4-s (Mixed DRL) schedule of reinforcement. In the first half of the Mixed DRL schedule, responses with an IRT $\geq 10$-s were reinforced. In the second half of the Mixed DRL schedule, responses with an IRT $\geq 4$-s were reinforced. The second schedule was a mixed DRL 10-s DRL 4-s Limited Hold 4-s (Limited Hold) schedule of reinforcement. In the second half of the Limited Hold schedule, responses with an IRT $\geq 4$-s and $\leq 8$-s were reinforced. The last schedule presented was a mixed DRL 10-s DRL 4-s Limited Hold 4-s with a point loss contingency (Cost). In the second half of the Cost schedule, responses with an IRT $\geq 4$-s and $\leq 8$-s were reinforced, while responses with an IRT < 4-s or $>8$-s resulted in the loss of one point. Like in the training phase, all tasks during testing lasted 6-min with the individual components of the mixed schedules alternating every 3-min. The presentation of the same initial component during two consecutive blocks did not occur (see Table 2 for the order of task presentations during the first testing session for all subjects).

Stability was calculated for all testing schedules after a minimum of three blocks. Response stability during each of the three testing schedules was achieved once visual inspection of the IRT distributions for the last three blocks did not show a systematic change in the overall distribution 
Table 2

Order of Task Presentations During the First Testing Session

\begin{tabular}{|c|c|c|}
\hline Block & Task & Length \\
\hline \multirow[t]{4}{*}{1} & $\begin{array}{l}\text { Dragging } \\
\text { Letters } \\
\text { Button }\end{array}$ & $\begin{array}{l}\text { 6-min } \\
6-\min \\
6-\min \end{array}$ \\
\hline & \multicolumn{2}{|c|}{$\begin{array}{l}\text { DRL 10-s component (3-min) } \\
\text { DRL 4-s component (3-min) }\end{array}$} \\
\hline & Roulette & 6-min \\
\hline & BREAK & 5-min \\
\hline \multirow[t]{3}{*}{2} & $\begin{array}{l}\text { Roulette } \\
\text { Button }\end{array}$ & $\begin{array}{l}\text { 6-min } \\
6-\min \end{array}$ \\
\hline & \multicolumn{2}{|c|}{$\begin{array}{l}\text { DRL 4-s component (3-min) } \\
\text { DRL 10-s component (3-min) }\end{array}$} \\
\hline & $\begin{array}{l}\text { Letters } \\
\text { Dragging }\end{array}$ & $\begin{array}{l}\text { 6-min } \\
6-\min \end{array}$ \\
\hline
\end{tabular}


of responses. During the first session of the testing phase, the "Button" task operated under the Mixed DRL schedule of reinforcement. Once response stability was present, the contingencies for the "Button" task changed to the Limited Hold schedule of reinforcement. Once stability was reached under the Limited Hold schedule, the contingencies for the "Button" task changed one last time to the Cost schedule.

The last screen presented to the subjects displayed the total number of points earned and also displayed a message stating that the subject should call the experimenter. Furthermore, subjects received a slip of paper indicating how much money they had earned in the session. Each point was worth $3 / 4$ of a cent $(.075 \varnothing)$. The daily earnings receipt included a $\$ 1.00$ bonus paid contingent on the completion of the experiment. A record of how much money was owed to each subject was kept. Upon completion of the experiment, all subjects completed an Exit Questionnaire. This questionnaire contained several questions that required subjects to report on what they thought had to be done during each task to obtain points. This questionnaire also asked subjects whether they had detected any changes in the contingencies at any point during the experiment. Once this questionnaire was completed, subjects were paid for their participation in the study. Subjects were debriefed once all data were collected.

Results

$\underline{\text { Training }}$

Ten subjects completed the experiment. Two IN subjects were excluded because they did not meet the accuracy criteria after seven training sessions. Two other subjects were excluded because of computer problems. Table 3 shows the number of training blocks needed by the 10 subjects to reach the stability criteria, their earnings, and the average amount of money earned 
Table 3

Number of Training Blocks of Trials, Money Earned, and Average Amount of Money Earned per Block for All Subjects

\begin{tabular}{|c|c|c|c|c|}
\hline Group & Subject & $\begin{array}{l}\text { Training Blocks } \\
\text { of Trials }\end{array}$ & $\begin{array}{l}\text { Money } \\
\text { Earned }\end{array}$ & $\begin{array}{l}\text { Average Money } \\
\text { Earned per Block }\end{array}$ \\
\hline \multirow[t]{6}{*}{ Accurate } & $\mathrm{AC} 1$ & 10 & $\$ 80.71$ & $\$ 2.69$ \\
\hline & $\mathrm{AC} 2$ & 10 & 59.34 & 2.37 \\
\hline & AC 3 & 6 & 77.97 & 3.12 \\
\hline & $\mathrm{AC} 4$ & 5 & 76.81 & 3.07 \\
\hline & $\mathrm{AC} 5$ & 10 & 67.75 & 2.95 \\
\hline & Average & 8.2 & 72.52 & 2.84 \\
\hline \multirow[t]{6}{*}{ Inaccurate } & IN 1 & 10 & 72.11 & 3.28 \\
\hline & IN 2 & 9 & 75.60 & 3.44 \\
\hline & IN 3 & 10 & 79.82 & 2.85 \\
\hline & IN 4 & 8 & 49.79 & 2.49 \\
\hline & IN 5 & 10 & 71.42 & 3.25 \\
\hline & Average & 9.4 & 69.75 & 3.06 \\
\hline
\end{tabular}


per block. Although there were some differences among subjects on these variables, none of the differences appear related to the kind of instruction presented. Even the number of training blocks required by the Accurate Instructions (AC) group and the Inaccurate Instructions (IN) group was similar with averages of 8.2 and 9.4, modes of 10 and 10, and ranges of 5 to 10 blocks and 8 to 10 blocks respectively.

Figure 5 shows more clearly the differences in training performance for the two groups. This figure displays the percent correct responding during training on all four tasks for a representative subject from the AC and IN groups (AC 1 and IN 1 respectively) and for Subject AC 5. Accuracy for AC 1 was close to $100 \%$ from the beginning of the experiment (top panel). Her behavior required 10 sessions to meet the stability criteria because of the slight variability found in two of the four tasks. Data for AC 1 are representative of the training data for three of the other four AC subjects (see Appendix C). Accuracy for IN 1 (middle panel) was more variable during the initial training blocks on three of the four tasks. By block 5, responding on all four tasks began stabilizing. These data are representative of the other IN subjects' training data (see Appendix D). The training accuracy in the "Button" task for AC 5 (bottom panel) more closely resembled the training accuracy in this task for IN 1. Although AC 5 was accurately instructed to press the button every 10-s, her accuracy on the "Button" task fluctuated from 0 to 100 percent and only stabilized after the eighth training block.

Figure 6 further illustrates that AC 5's behavior during the training of the "Button" task more closely resembled that of an inaccurately instructed subject. This figure shows the average IRT, with its standard deviation, obtained during each training block of the "Button" task for Subjects AC 1, IN 1, and AC 5. The average IRT during training was obtained by adding the individual 


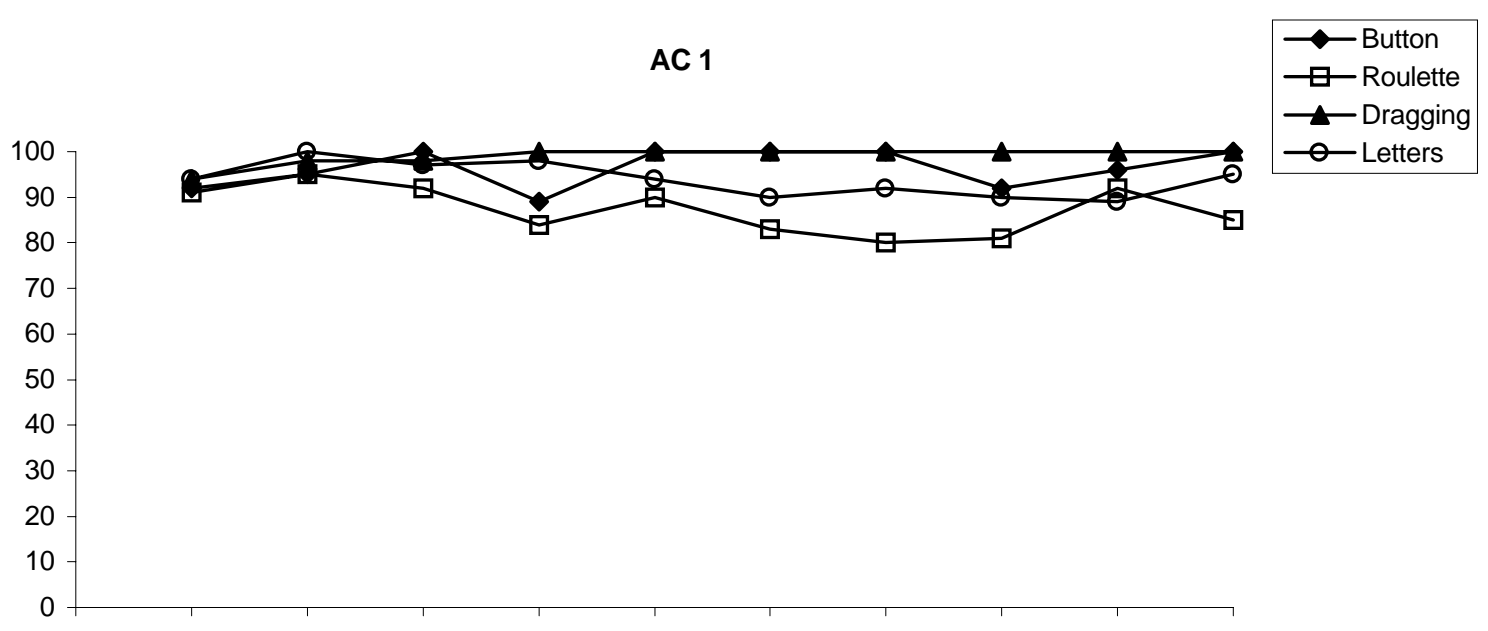

IN 1

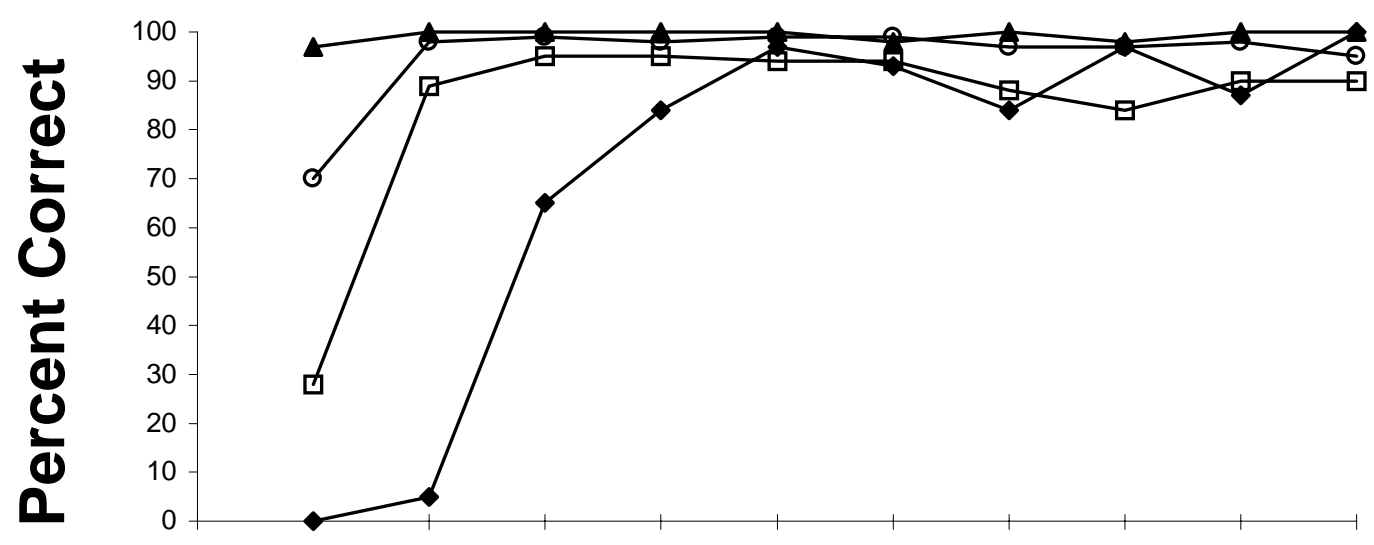

AC 5

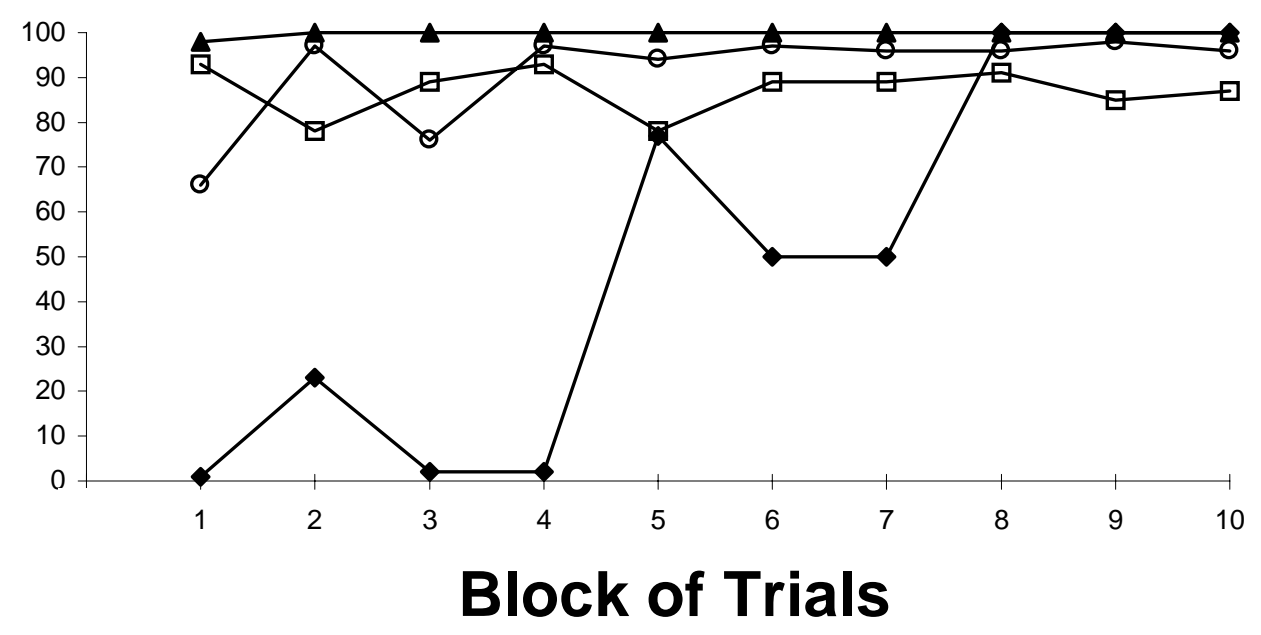

Figure 5. Training accuracy across all tasks for representative subjects. 
AC 1

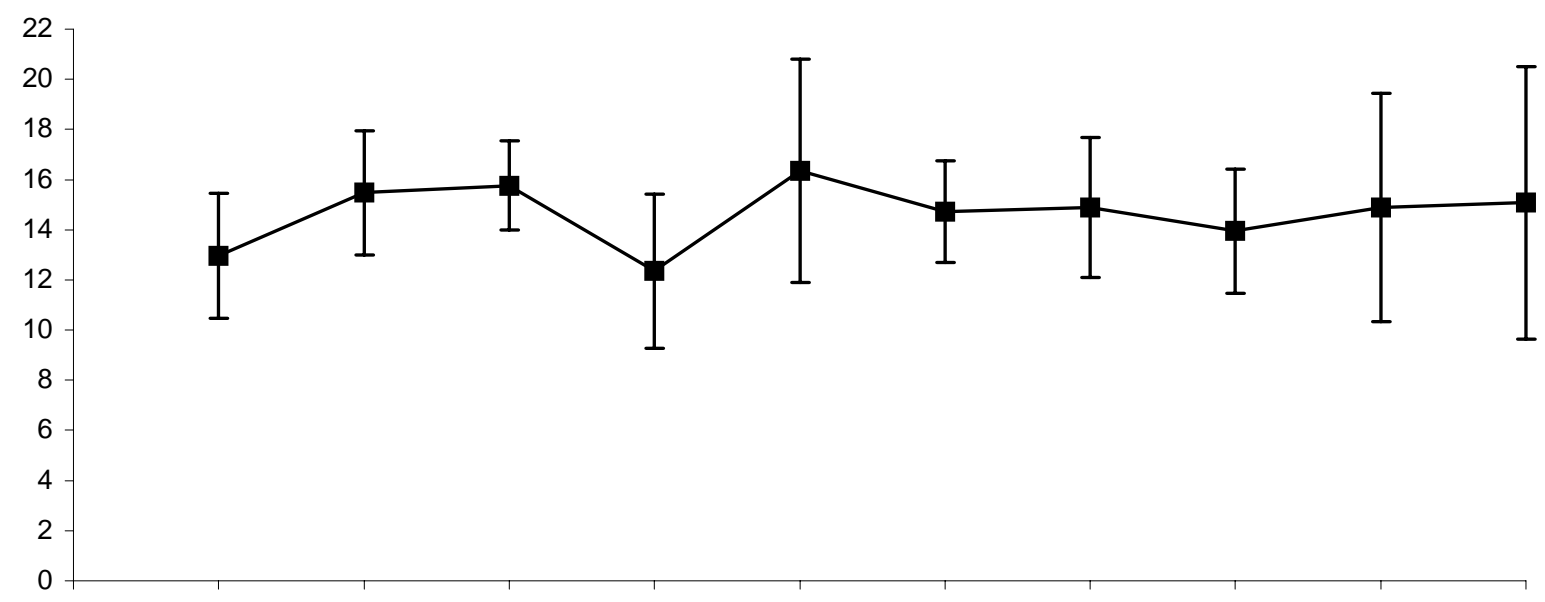

IN 1

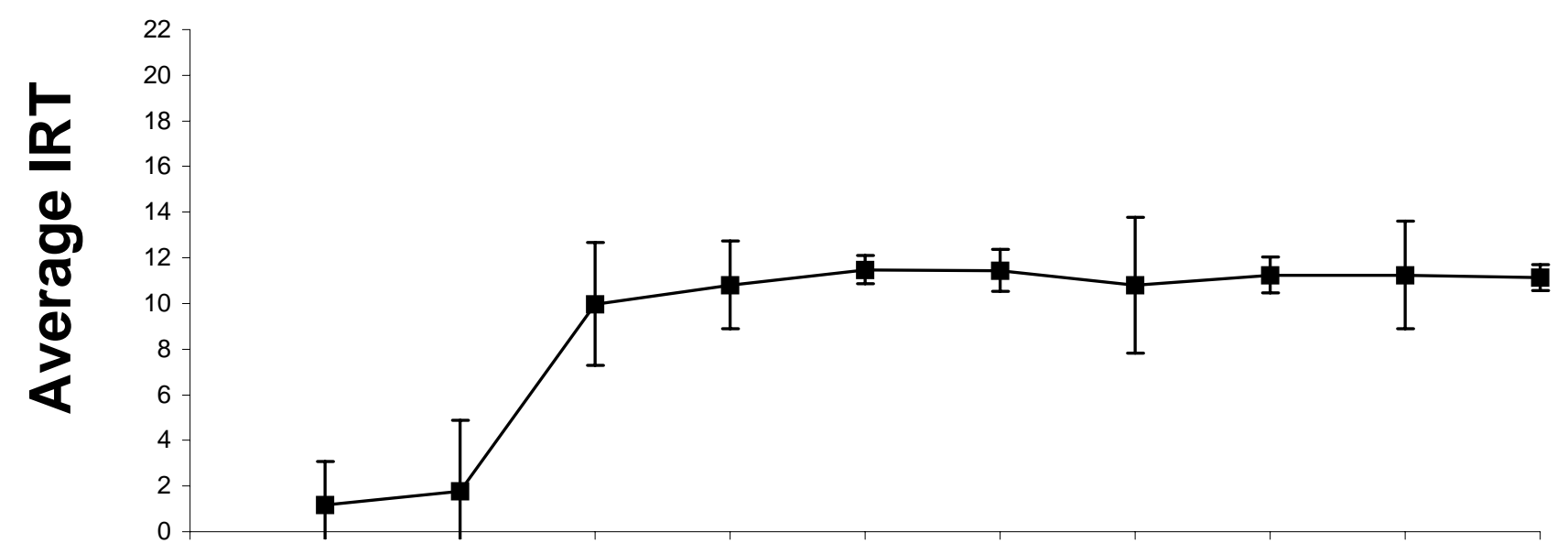

AC 5

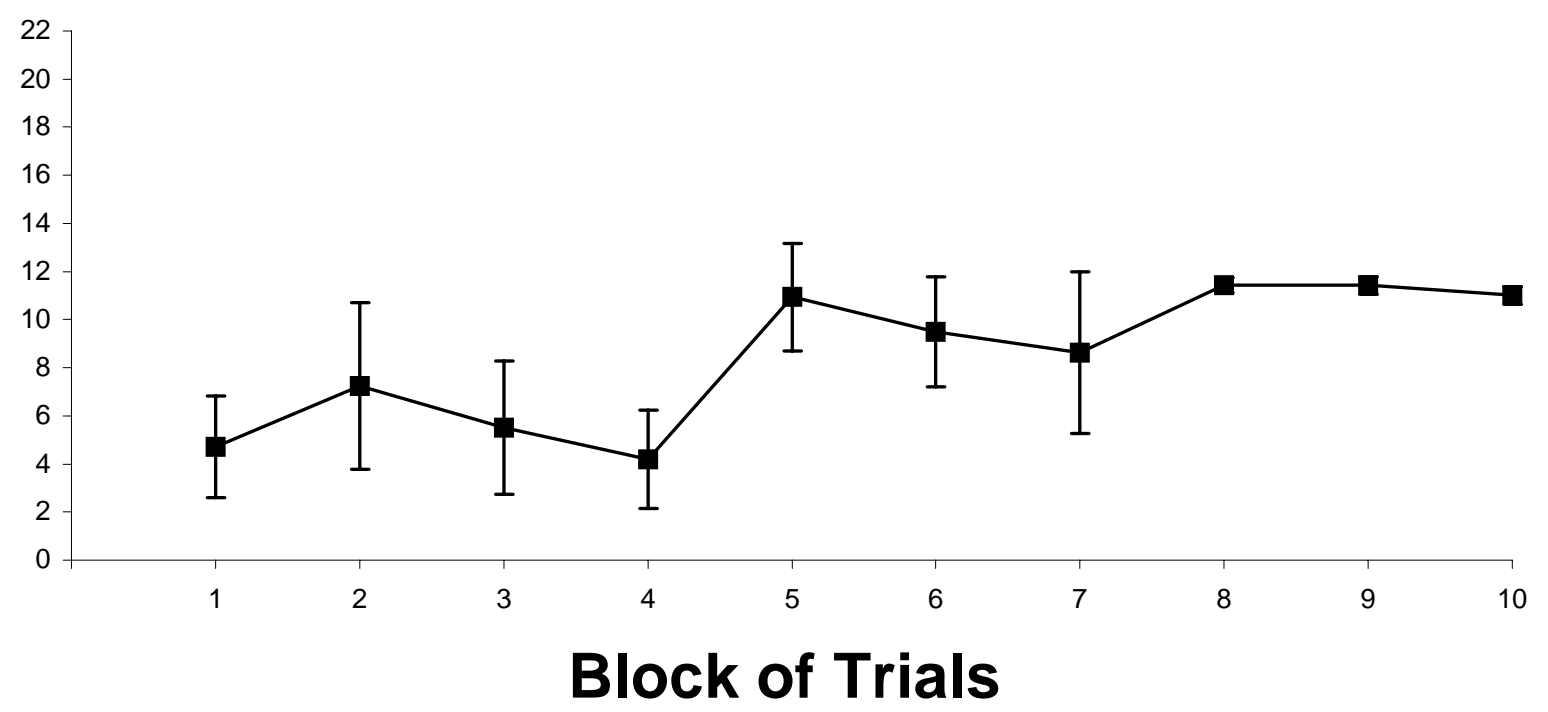

Figure 6. Average interresponse times during training for representative subjects. 
IRTs during each block and dividing this number by total block length, 6-min. The average IRT during the first four training blocks was 14.14-s with an average standard deviation of \pm 2.46 -s for AC 1 (top panel). The average IRT for IN 1's first four training blocks was 5.94-s with a \pm 2.40 -s average standard deviation (middle panel). Subject AC 5's graph (bottom panel) shows that her average IRT during the first four training blocks was 5.42-s with an average standard deviation of \pm 2.60 -s.

\section{Testing}

Only during the "Button" task did the behavior of the subjects change with the transition from training to testing. Sensitivity to these contingency changes for each subject was assessed by analyzing the following: (a) whether the IRTs distribution obtained from the last three blocks of each test condition differed from the IRT distribution obtained from the last three training blocks ("Training-Test" sensitivity); (b) whether the IRTs distribution obtained from the last three blocks of the Limited Hold and Cost conditions differed from the IRT distribution obtained from the last three blocks of the previous test condition (“Test-Test" sensitivity); (c) whether differential responding was observed in the presence of the individual testing components during each of the three testing conditions ("Component" sensitivity); and (d) whether more points were earned under the 4-s component than under the 10-s component in each of the three testing conditions.

Although there were some differences between groups on these four types of analyses, the only difference related systematically to the kind of instruction presented (accurate vs. inaccurate) was whether more points were earned in "Button" task under the 4-s component than 
under the 10-s component in each of the three testing conditions. Therefore, these data are presented first.

Points Earned

Representative Subjects. Figure 7 shows the number of points earned during training and during both components of all testing conditions by Subjects AC 1, IN 1 and IN 2. The upper panel shows that AC 1 earned approximately the same number of points under the two Mixed DRL components (an average of 7.4 points per block under each component). During the next testing condition, $\mathrm{AC} 1$ earned an average of 8.4 points per block during the 10-s component, while failing to earn any points under the 4-s Limited Hold component. Finally, under the Cost schedule, AC 1 earned an average of 6 points per block under the 10-s component, while losing an average of 6 points per block under the 4-s Cost component. These data typify the number of points earned and lost for three of the other four AC subjects (see Appendix E).

The middle panel on Figure 7 shows the number of points IN 1 earned. During the first testing condition, IN 1 earned approximately the same number of points under both Mixed DRL components (an average of 14.4 points per block under each component). During the next testing condition, on the other hand, IN 1 earned more points under the 4-s component than under the 10-s component (an average of 27.5 and 12.5 points per block, respectively). This differential earnings of points was also observed under the Cost condition where IN 1 earned an average of 13.33 points per block under the 10-s component while earning an average of 27 points per block under the 4-s component. Subject IN 4 (see upper panel in Appendix F) responded similarly to Subject IN 1. 
AC 1

-10-Training
$-\mathbf{- 1 0 - s}$
$-\mathbf{0}-4-\mathrm{s}$

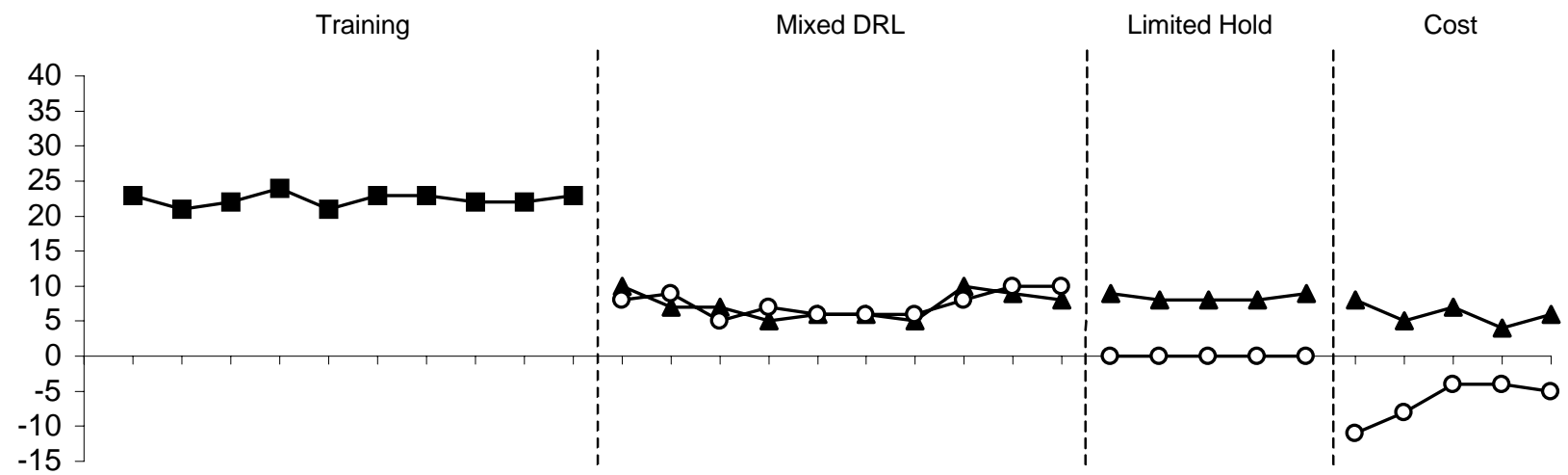

$\begin{array}{lllllllllllllllllllllllllllllll}1 & 2 & 3 & 4 & 5 & 6 & 7 & 8 & 9 & 10 & 11 & 12 & 13 & 14 & 15 & 16 & 17 & 18 & 19 & 20 & 21 & 22 & 23 & 24 & 25 & 26 & 27 & 28 & 29 & 30\end{array}$

IN 1

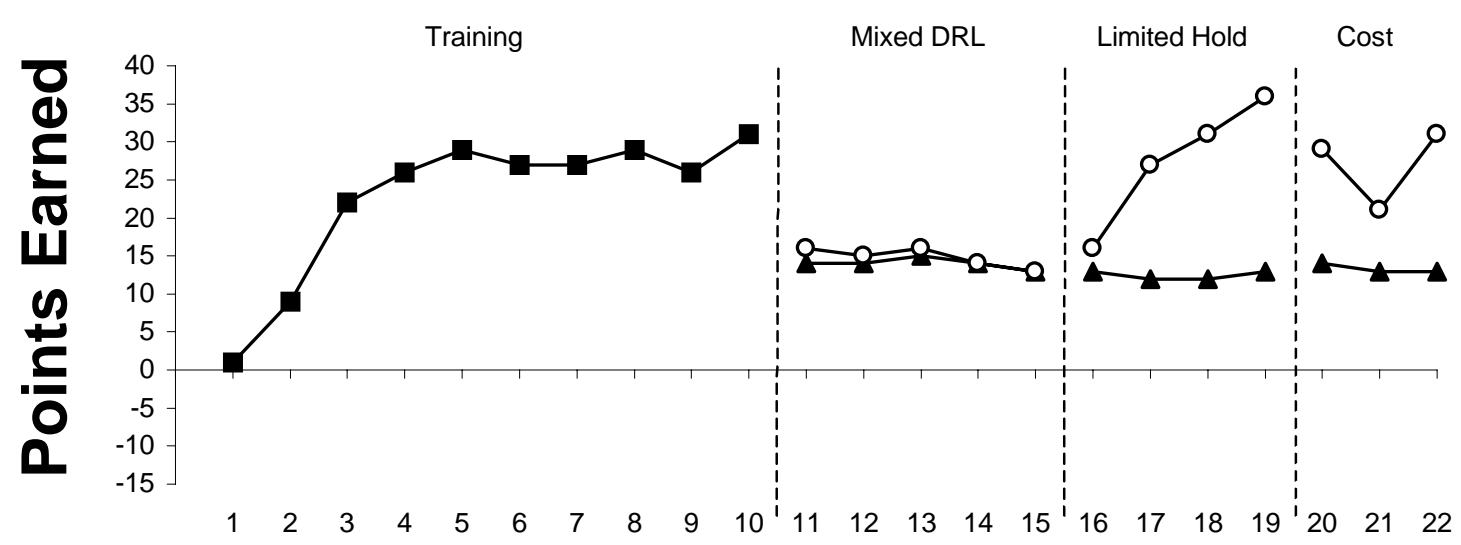

IN 2

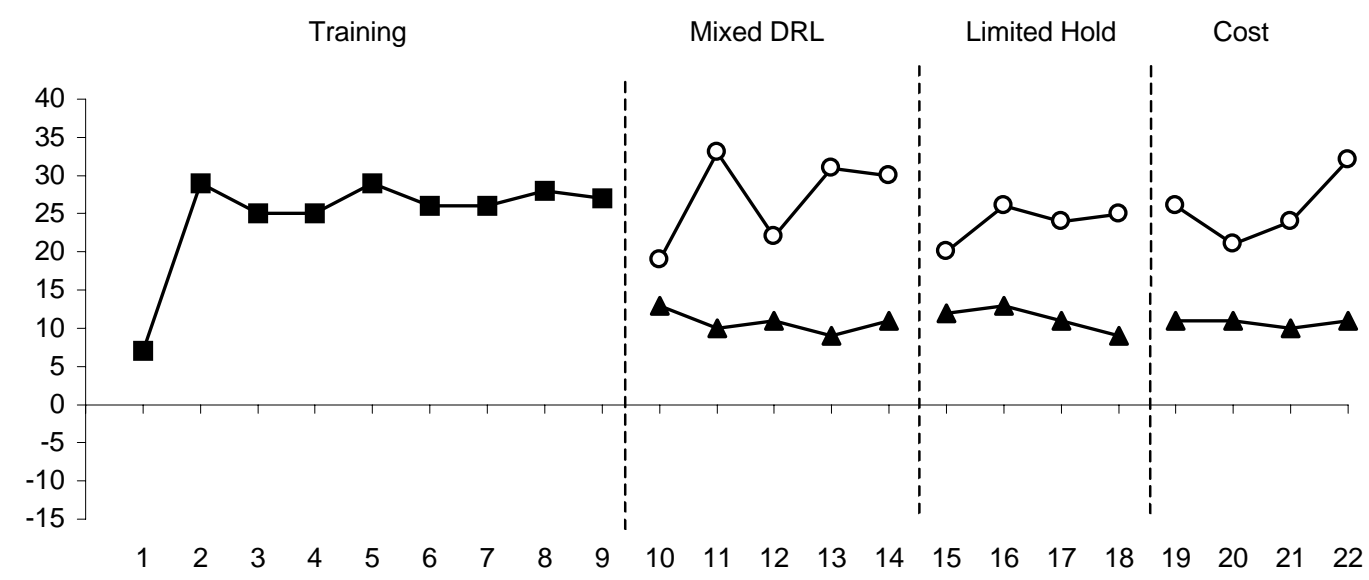

\section{Block of Trials}

Figure 7. Points earned across conditions for representative subjects. 
The lower panel on Figure 7 presents the number of points earned by IN 2. This subject earned more points under the 4-s components than under the 10-s components of all testing conditions. During the Mixed DRL condition, IN 2 earned an average of 10.8 points per block under the 10-s component while earning an average of 27 points per block under the 4-s component. This differential earnings of points continued during the Limited Hold and Cost conditions. Under the 10-s components of the Limited Hold and Cost conditions, IN 2 earned an average of 11.25 and 10.76 points per block, respectively. Under the 4-s components of these two conditions, IN 2 earned an average of 23.75 and 25.76 points per block. IN 2's data are characteristic of the number of points earned by Subject IN 3 (see lower panel in Appendix F).

Outlier Subjects. Each group had a subject whose behavior differed from the behavior of the other group members. As previously mentioned during the summary of the training data, AC 5 behaved more like an inaccurately instructed subject during training of the "Button" task (see Figures 5 and 6). Consequently, she was the only AC subject who responded like most IN subjects under the Limited Hold and Cost conditions (i.e., she was the only AC subject who earned more points under the 4-s than the 10-s components of the Limited Hold and Cost schedules). The upper panel on Figure 8 illustrates these differences by showing the number of points AC 5 earned across training and testing conditions. Under the Mixed DRL condition, AC 5 earned approximately the same number of points under both testing components (an average of 14.17 points per block during each component). Under the Limited Hold and Cost schedules, AC 5 earned more points under the 4-s components than under the 10 -s components. Under the 10 -s components of the Limited Hold and Cost conditions, AC 5 earned an average of 8.72 and 11.33 


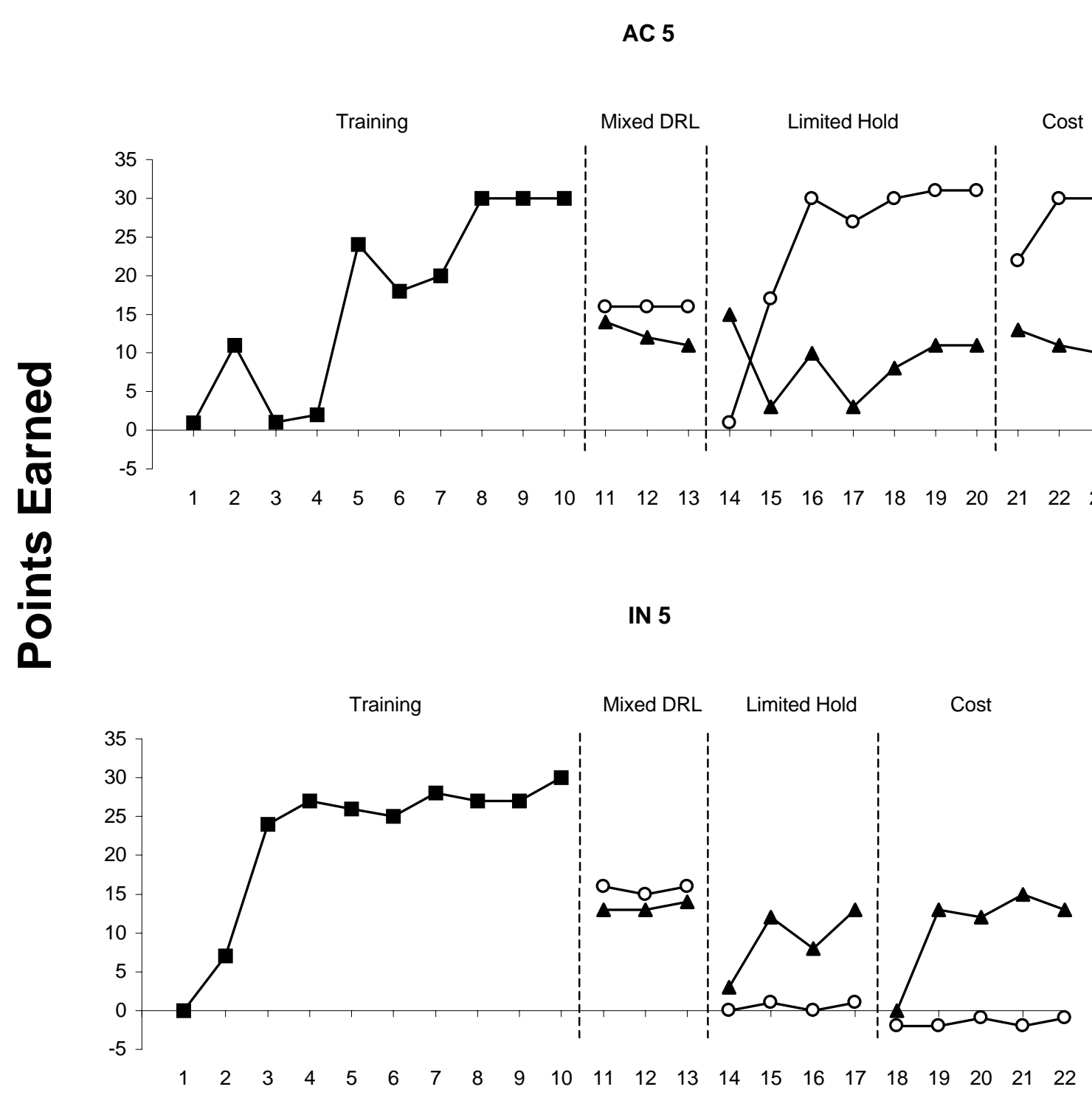

\section{Block of Trials}

Figure 8. Points earned across conditions for outlier subjects. 
points per block, respectively. During the 4-s components of these two conditions, AC 5 earned an average of 23.86 and 27.33 points per block.

The lower panel on Figure 8 shows the number of points earned by the only subject from the IN group who did not earn more points under the 4-s components throughout most of the testing conditions. During the Mixed DRL condition, IN 5 earned approximately the same number of points under both testing components (an average of 14.50 points per block during each component). During the Limited Hold condition, IN 5 earned an average of 9 points per block under the 10-s component, while only earning an average of .50 points per block under the 4-s component. IN 5 continued earning points under the 10-s component of the Cost schedule (an average of 10.60 points per block), while losing an average of 1.60 points per block during the 4s component.

\section{Other Measures of Sensitivity}

As stated earlier, other measures of sensitivity did not vary systematically between the AC and IN groups. Differences that might be of interest, however, did emerge among subjects. The number of subjects whose behavior changed between training and testing conditions and among different types of testing conditions varied depending on the testing schedule in effect.

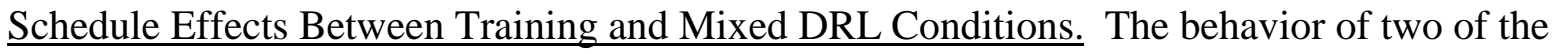
five AC subjects (AC 1 and AC 2) changed between training and Mixed DRL testing conditions. Figure 9 shows the IRTs distributions presented in 2-s bins for the last three training blocks and for the last three 10-s and 4-s Mixed DRL component blocks for one of the three AC subjects whose behavior did not change (AC 3) and for the two AC subjects whose behavior did change (AC 1 and AC 2). Note that the vertical scale for the upper panel is different from the vertical 
AC 3

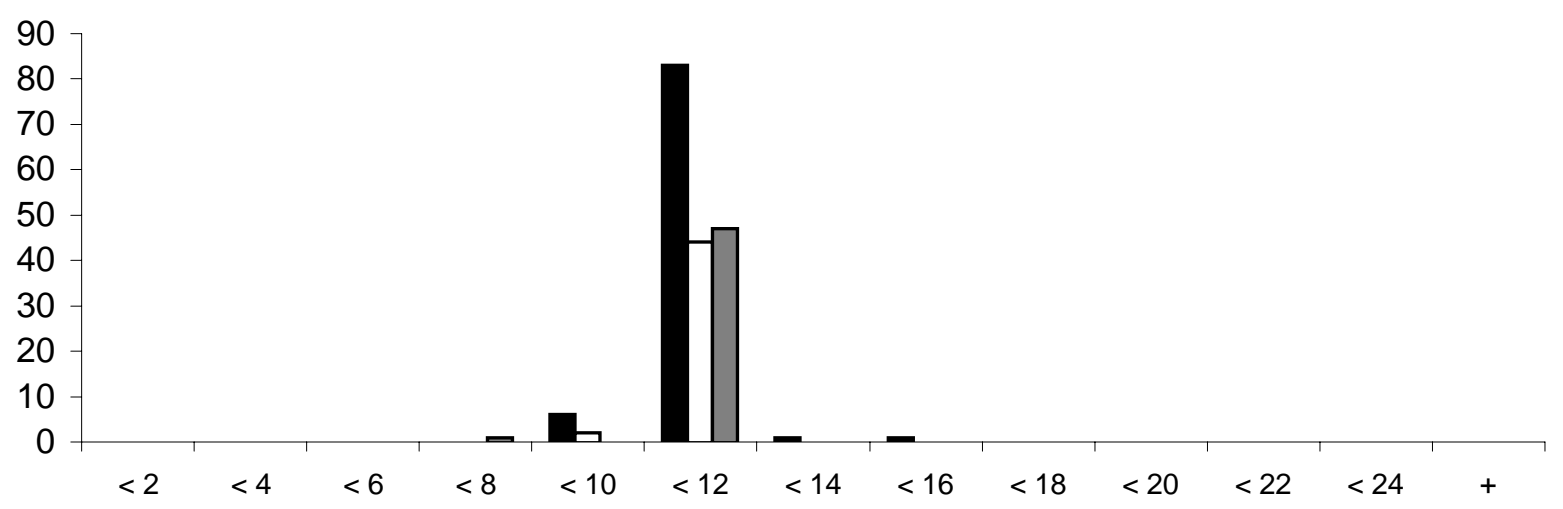

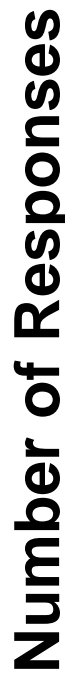

AC 1

פ

30

25

20

15

10

0

$<2$

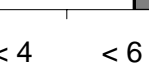

$<8$

$<10$

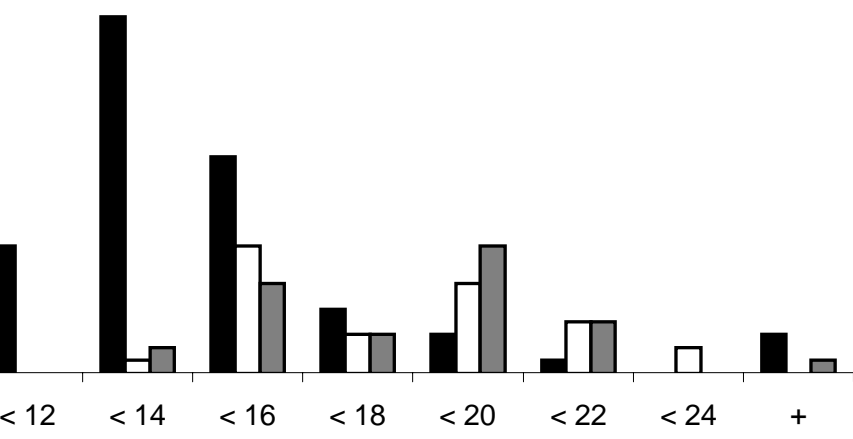

AC 2

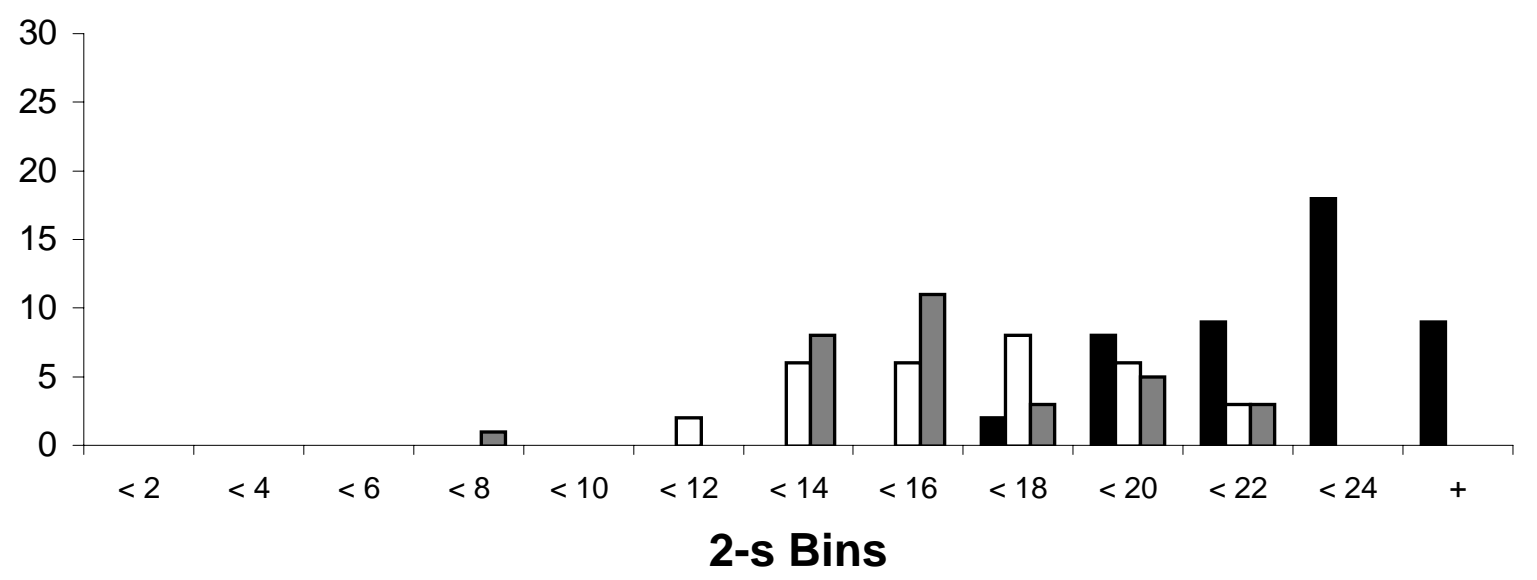

Figure 9. Interresponse times distributions in 2-s bins across training and Mixed DRL conditions for three representative AC subjects. Bin labeled "+" shows the frequency of interresponse times longer than 24-s. 
scale of the other two panels. The upper panel shows that Subject AC 3's modal IRT during training (black bars) and during the Mixed DRL condition (white and shaded bars) was between 10 and 12-s. The differences in number of responses per bar is due to the different component lengths. The training IRTs (black bars) represent 18-min worth of data, while the Mixed DRL IRTs (white and shaded bars) each represents 9-min worth of data. The IRTs for Subject AC 1 (middle panel) were longer in the Mixed DRL condition than in the training condition. During training, the modal IRT was between 12 and 14-s (black bars), while most of the IRTs by the end of the Mixed DRL condition were between 14 and 16-s and between 18 and 20-s (white and shaded bars). The bottom panel of Figure 9 shows that AC 2's rate of responding during the last three Mixed DRL blocks increased relative to her training data. Responding on the two components, however, appears undifferentiated for these AC subjects. For AC 3 (upper panel), AC 1 (middle panel) and AC 2 (lower panel), the distributions under the 10-s component (white bars) were similar to the IRT distributions under the 4-s component (shaded bars).

The behavior of three of the five subjects in the IN condition (IN 1, IN 4, and IN 5) was not sensitive to the change from training to Mixed DRL testing. Figure 10 contains the IRTs distributions of the last three training blocks and of the last three 10-s and 4-s Mixed DRL component blocks for one of these IN subjects (IN 5) and for one of the two IN subjects whose behavior changed (IN 2). The upper panel shows that Subject IN 5's IRTs distributions under the training and Mixed DRL conditions were similar. During both conditions, the modal IRT was between 10 and 12-s. The lower panel shows that most of Subject IN 2's IRTs under training and under the 10-s Mixed DRL component were between 10 and 12-s (black and white bars). The modal IRT during the 4-s component of the Mixed DRL schedule (shaded bars), however, was 
IN 5

Last 3 training blocks

口Last 3 blocks in Mixed DRL 10-s component

口Last 3 blocks in Mixed DRL 4-s component

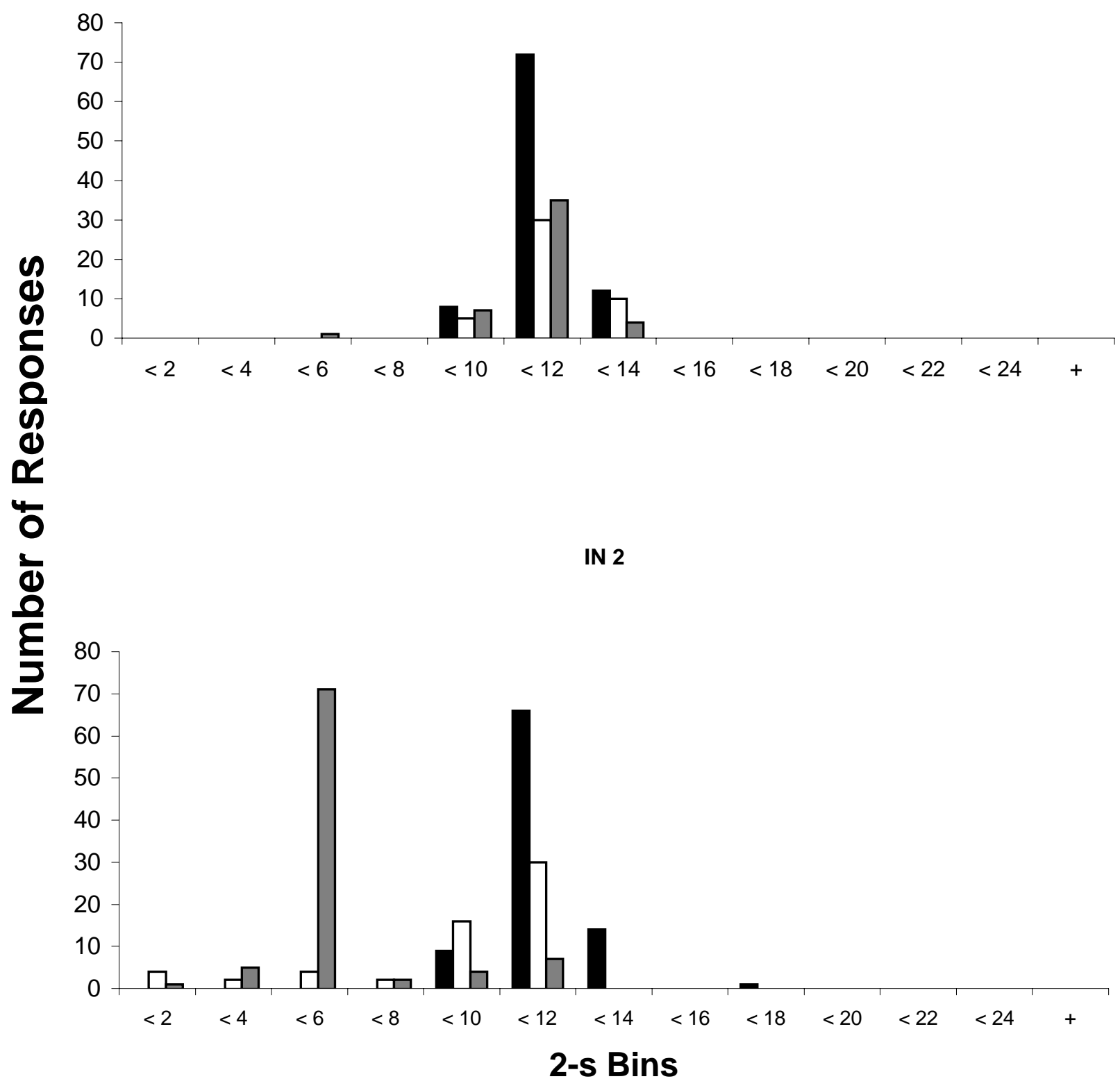

Figure 10. Interresponse times distributions in 2-s bins across training and Mixed DRL conditions for two representative IN subjects. Bin labeled "+" shows the frequency of interresponse times longer than 24-s. 
between 4 and 6-s. This also shows that the behavior of IN 2 varied between Mixed DRL components because the modal IRT during the 10-s component differed from the modal IRT during the 4-s component.

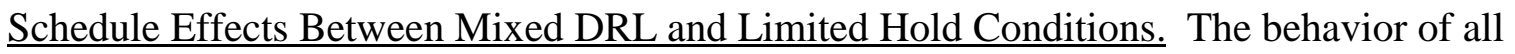
AC subjects and of four of the five IN subjects (IN 1, IN 3, IN 4 and IN 5) changed with the transition from Mixed DRL to Limited Hold testing conditions. The only subject whose behavior did not change between these conditions was IN 2 . She was the only subject who earned more than twice the number of points under the 4-s Mixed DRL component than under the 10-s Mixed DRL component, thus reaching a ceiling on the 4-s component. Figure 11 shows the IRTs distributions presented in 2-s bins for both components of the last three Mixed DRL and last three Limited Hold blocks for the subject whose behavior did not change (IN 2) and for one of the nine subjects whose behavior changed (AC 3). The upper panel shows that IN 2's distributions between testing schedules were similar. While the modal IRT under the 10-s component of both the Mixed DRL and Limited Hold schedules (black and shaded bars) was between 10 and 12-s, the modal IRT under the 4-s component of both schedules (white and diagonal striped bars) was between 4 and 6-s. The lower panel on Figure 11 shows that AC 3's modal IRT during both components of the Mixed DRL schedule (black and white bars) and during the 10-s component of the Limited Hold schedule (shaded bars) was between 10 and 12-s. Under the 4-s Limited Hold component (diagonal stripped bars), AC 3's modal IRT was more than 24-s with most responses distributed between 14 and more than 24-s.

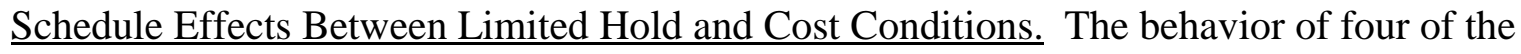
five AC subjects (AC 1, AC 2, AC 3, and AC 4) and one of the five IN subjects (IN 5) continued 


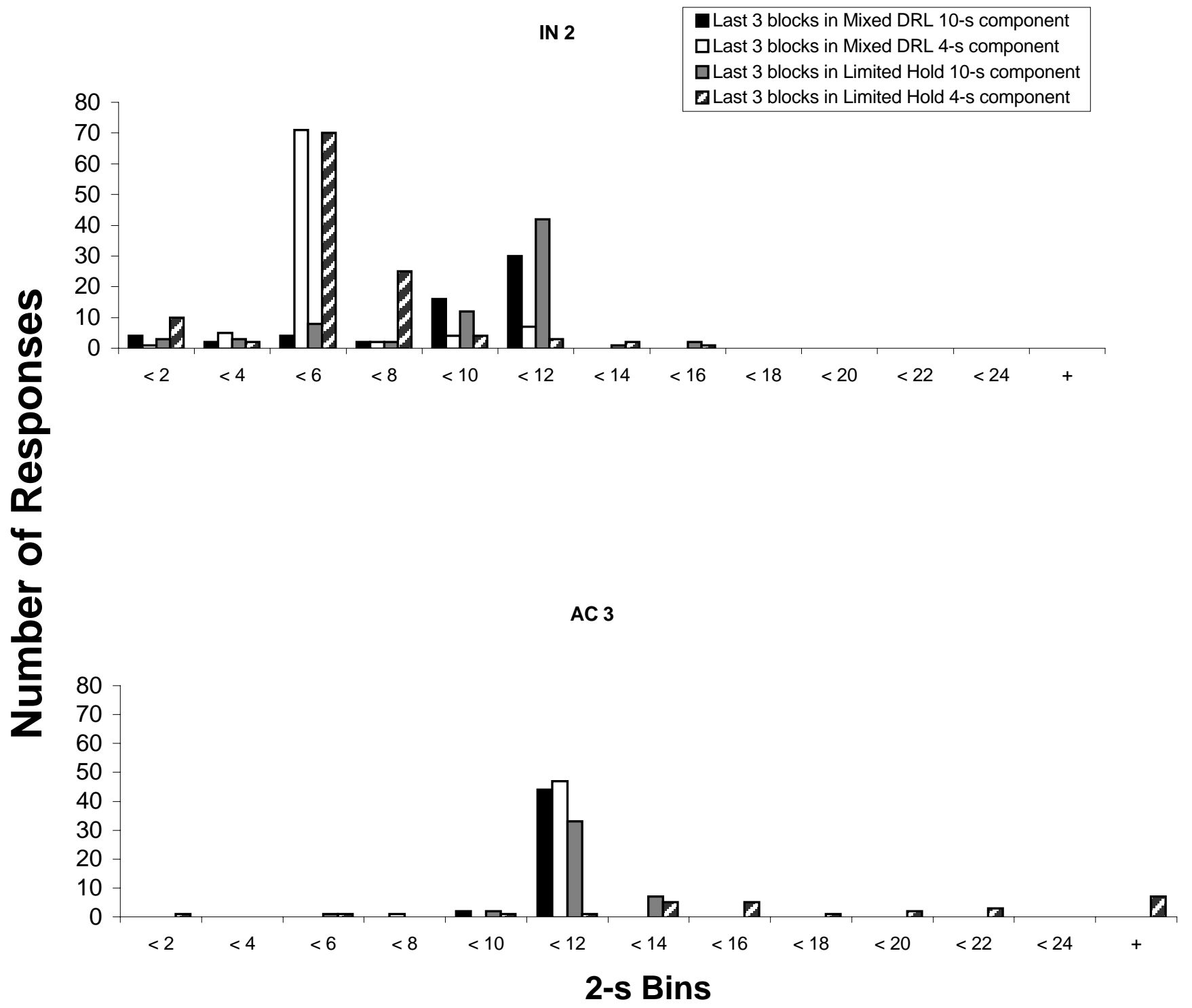

Figure 11. Interresponse times distributions in 2-s bins across Mixed DRL and Limited Hold conditions for two representative subjects. Bin labeled "+" shows the frequency of interresponse times longer than 24-s. 
to change between Limited Hold and Cost conditions. Whether or not a subject's behavior changed between these two conditions was related to whether the subject had earned more points under the 4-s component than under the 10-s component of the Limited Hold condition. Figure 12 illustrates these results by showing the IRTs distributions for both Limited Hold and Cost conditions for one subject whose behavior did not change (IN 1) and for a subject whose behavior did change (IN 5). Note that the vertical scale is different for each panel. The upper panel shows that for IN 1, responding under the 10-s Limited Hold component (black bars) was similar to the responding under the 10-s Cost component (shaded bars). Likewise, her responding under the 4-s Limited Hold component (white bars) was similar to her responding under the 4-s Cost component (diagonal stripped bars). The bottom panel, on the other hand, shows that IN 5's IRT distribution under the 4-s Limited Hold component (white bars) differed from her IRT distribution under the 4-s Cost component (diagonal stripped bars). Very few IRTs under the 4-s Cost component can be observed because this subject stopped responding whenever the 4-s Cost component was in effect.

\section{Discussion}

This study examined how a history of reinforcement for following or not following rules affects the sensitivity of behavior to programmed changes in the environment. Two groups of subjects were provided with a training history where reinforcement could be obtained by either following (AC group) or not following (IN group) instructions on four tasks. Once stability criteria were met during training, the scheduled contingencies for one of the four tasks changed. Instead of providing reinforcers on a DRL 10-s schedule of reinforcement as during training, three different types of mixed schedules (Lamons \& Chase, 1992) were presented to the subjects: 


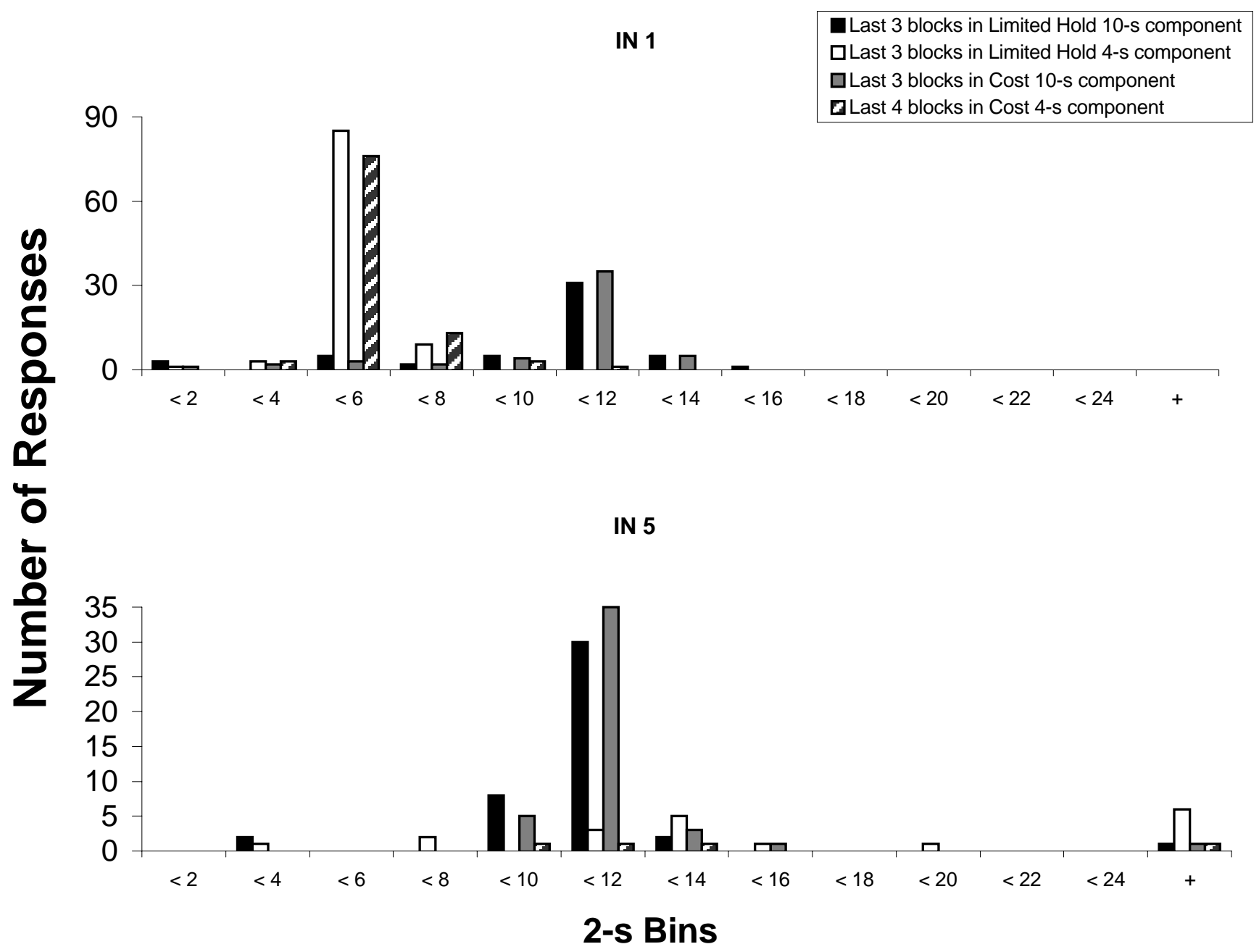

Figure 12. Interresponse times distributions in 2-s bins across Limited Hold and Cost conditions for two representative subjects. Bin labeled "+" shows the frequency of interresponse times longer than 24-s. 
DRL 10-s DRL 4-s (Mixed DRL), DRL 10-s DRL 4-s Limited Hold 4-s (Limited Hold), and DRL 10-s DRL 4-s Limited Hold 4-s with a point loss contingency (Cost). It was predicted that the behavior of the IN group would be more sensitive to changes in the experimental contingencies.

Sensitivity to these changes was assessed by conducting a series of analyses. One of these analyses, whether more points were earned under the 4-s components of the testing schedules than under the 10-s components, resulted in clear differences between groups. Subjects who were presented with inaccurate instructions were more likely to earn reinforcers during both components of the mixed schedules, while subjects who were presented with accurate instructions were more likely to earn points only during the 10-s components. Other analyses revealed differences in sensitivity related to the kind of test schedule in effect. For the most part, subjects' performances were sensitive to changes in schedules that provided differential contact with the reinforcers (Galizio, 1979). However, some interesting individual subject exceptions were noted. The following presents a detailed discussion of these data with suggestions for future research.

\section{Differences Between Groups}

The behavior of four of the five AC subjects did not come under the control of the differential number of points available during testing. Only Subject AC 5 usually earned more points under the 4-s components than under the 10-s components of the test schedules. The other AC subjects usually emitted longer IRTs during testing that, consequently, were never reinforced. These longer IRTs indicated that the behavior was sensitive to a difference between the 10-s 
component and the 4-s Limited Hold component, but was not sensitive to the availability of points during this latter component. When the Cost condition was implemented, most AC subjects ceased to respond either during the 4-s Cost component or during both components of this mixed schedule. This suppression of responding appears to be due to the sensitivity of their behavior to the loss of points, but not to the availability of points under the 4-s Cost component.

In contrast, the behavior of four of the five IN subjects was sensitive to the differential availability of points. These subjects earned, on average, more than twice the number of points under the 4-s components than under the 10-s components of most testing schedules. Two of the IN subjects showed differential responding sufficient to produce reinforcement during both components of the Mixed DRL condition, while four IN subjects showed differential responding sufficient to produce reinforcement under both components of the Limited Hold and Cost conditions. The behavior of most IN subjects, then, was sensitive to the Limited Hold and Cost schedules of reinforcement. Only the behavior of Subject IN 5 did not come under the control of this differential availability of points.

These differences between groups might be explained by examining the subjects' training histories within the experiment. The IN subjects, unlike the AC subjects, were presented with an instruction during the "Button" task that indicated that reinforcers would be provided for producing high rates of behavior. All IN subjects emitted a high number of short IRTs, usually during the first two training blocks. The AC subjects, on the other hand, were instructed to emit IRTs equal to 10 -s from the beginning of training. When contingencies changed so that IRTs $\geq$ 10-s were extinguished, most IN subjects emitted high rates of behavior while most AC subjects 
slowed down. Thus, an experimental history of high-rate responding is correlated with the occurrence of high rates under the 4-s components of the testing schedules.

Studies on resurgence may be used to explain, at least in part, why a history of responding at high rates may be correlated with high rate performance on the tests. Resurgence applies to situations where a previously reinforced behavior recurs when a recently reinforced behavior is placed on extinction (Epstein, 1985). It is suggested that when extinction was implemented during the Limited Hold condition in the present study, short IRTs resurged for most IN subjects. Because short IRTs between 4 and 8-s were reinforced during testing, they continued to be emitted. The AC subjects, on the other hand, did not have a history of emitting short IRTs and thus, when extinction was implemented, short IRTs were not likely to resurge.

This explanation is not completely adequate for the current results, however, because in experiments where resurgence has been examined, the behavior under examination has always been directly reinforced (e.g., Epstein, 1983; Epstein \& Skinner, 1980; Rawson, Leitenberg, Mulick, \& Lefebvre, 1977; however, for an alternative perspective, see Wilson \& Hayes, 1996). In the present study, short IRTs were never directly reinforced. Nonetheless, although short IRTs were never reinforced with points for the IN subjects, emitting these short IRTs were, at least initially, under instructional control. Perhaps instructed behavior that has a history of reinforcement may resurge similarly to behavior that has been explicitly reinforced within an experiment. 


\section{Group Outliers}

Both groups had one subject who performed differently from the other members of the group. Subject AC 5's behavior contacted the differential availability of points early in the test and showed sensitivity to the differences in the schedules similar to the IN subjects. This may be explained by examining her training data. She was the only AC subject who behaved like an IN subject during the training of the "Button" task. Although she was presented with instructions that specified that points could be earned by waiting 10 -s before pressing the button labeled "Earn," she did not follow this instruction. Thus, she was the only AC subject whose buttonpressing behavior during training seems to have had direct contact with the contingencies and might not have been acquired simply through the verbal specifications of said contingencies. Consequently, she was the only AC subject whose behavior occurred at high rates during testing. When her behavior contacted a change in the schedules during the Limited Hold and Cost testing conditions, these high rates of behavior contacted the increased availability of reinforcement under the 4-s components. Her data add to the correlation specified between high rates during training and high rates during testing described above for the IN subjects. It should be noted that although her training and testing data under the "Button" task were very similar to those obtained for the IN subjects, it is not known what variables were controlling AC 5's training performance. The only factor manipulated during training, the type of instruction presented, clearly did not control her rate of responding.

Subject IN 5, whose behavior was different from the behavior of the other four IN subjects, may have been exposed to a critical procedural difference. During the first 3 minutes of both the Limited Hold and Cost testing phases, she was presented with the 4-s component of 
these mixed schedules. The other IN subjects were presented with the 10-s component during the first 3 minutes of all testing conditions. Subject IN 5's behavior may have been insensitive to the differential number of points available because the extinction component was contacted immediately. Why this would lead to an indifference to the availability of points is not known. Because the order of presentation of the testing components was not manipulated systematically, further research, which will be described later, should be conducted to investigate this issue.

\section{Differences Between Conditions: Training to Mixed DRL Testing}

Although other tests of sensitivity did not find systematic differences between groups, some consistencies were found across all subjects in the different testing conditions. For example, during the Mixed DRL condition the behavior of most subjects was not sensitive on any measure to the differences between components. An analysis of the IRTs distributions of the last three blocks of training and the last three blocks of the Mixed DRL condition showed no changes in behavior for 6 of the 10 subjects. Furthermore, 8 of the 10 subjects earned approximately an equal number of points under the two Mixed DRL components.

This result was expected because the Mixed DRL schedule did not necessarily produce a change in the environment for the subjects. If subjects continued to respond as they had during training, no differences should have been detected between the 10-s and the 4-s components. These IRTs analyses, however, did reveal that the behavior of two subjects from each group changed with the transition from training to Mixed DRL testing. This was an unanticipated result because previous research has shown that behavior is less likely to change if it is not forced into contact with the new scheduled contingencies (e.g., Buskist \& Miller, 1986; Galizio, 1979; 
Lamons \& Chase, 1992), although some researchers have concluded that contact alone is not sufficient for sensitivity to occur (e.g., Shimoff et al., 1981; Hayes et al., 1986).

In the present study, a number of possible controlling variables seemed to have affected the subjects' behavior that changed with the transition to the first testing condition. At least one of the AC subjects whose distribution shifted from training to Mixed DRL testing seemed to be responding to extra-experimental variables. An analysis of AC 2's IRT distributions showed that her rate of responding increased under both components of the Mixed DRL condition, although her behavior never contacted the differential availability of points. Subject AC 2 reported in her Exit Questionnaire that this change occurred because she had timed herself against the kitchen clock in her house between sessions. She reported that doing this led her to conclude that she was going too slow when counting to $10-\mathrm{s}$. Thus, it appears that factors outside the laboratory may have led to changes in her responding.

For one of the IN subjects whose behavior changed during the Mixed DRL schedule, IN 2 , it appears that variability in responding at the end of the training phase allowed behavior to contact the schedule changes in the Mixed DRL condition. Joyce and Chase (1990) found that procedures that allow response variability at the moment when contingencies change increase the sensitivity of behavior to environmental changes. Such variability may have been related to IN 2's performance, especially because the stability criteria used during training allowed for IRTs between 8 and 10-s to be emitted. For example, 10\% of the IRTs emitted by Subject IN 2 during the last three training blocks were between 8 and 10-s. She continued this pattern of responding during the first block of the Mixed DRL condition and this, in turn, led to the reinforcement of these shorter IRTs. Her IRTs continued to decrease until a lack of reinforcement for emitting 
IRTs less than 4-s was contacted, at which point her rate of responding under the 4-s Mixed DRL component stabilized. It should be noted, though, that procedures that produce variability in responding during training were not sufficient to produce changes in responding during the Mixed DRL condition. Other subjects showed similar variability during training, but their behavior did not contact the contingency changes. This probably means that there were other variables, perhaps extra-experimental, involved in the sensitivity observed in IN 2's behavior.

Additional arguments for the effects of extra-experimental variables are found in IN 3's and AC 1's behavior. Although IN 3's behavior was initially sensitive to the differential availability of points in the Mixed DRL condition, this sensitivity fluctuated across blocks in this condition. Starting with the second block of the Mixed DRL condition, IN 3 earned more points during the 4-s component than during the 10-s component. Nonetheless, by that condition's fifth block, the difference in number of points earned under each component had decreased, only to increase again during the sixth Mixed DRL block. By the end of this condition, approximately the same number of points was being earned under both components. This fluctuation suggests that IN 3's changes in responding were also determined, in part, by factors outside the experiment. Subject AC 1's behavior also indicated that the experiment did not control sufficiently for external factors. Her IRT distributions showed that rate of responding decreased once the Mixed DRL condition was presented. Her behavior did not contact the differential availability of points and she did not comment on this change during the post-experimental Exit Questionnaire. 


\section{Differences During Limited Hold and Cost Conditions}

The behavior of all subjects, except for the behavior of the only subject who was already earning points under both Mixed DRL components (IN 2), changed with the transition from Mixed DRL to Limited Hold conditions as assessed by examining subjects' IRTs distributions. The rate of responding for four of the five AC subjects decreased during the 4-s Limited Hold component. For example, while AC 3's modal IRT during both components of the Mixed DRL schedule was 10-s, the modal IRT during the 4-s Limited Hold schedule was more than 24-s. In addition, the rate of responding for four of the five IN subjects increased or decreased during the 4-s Limited Hold component. These results support the conclusions reached by Galizio (1979) that behavior only changes when direct contact with the programmed changes is made. The change in most of the testing conditions of the current experiment led to the absence of reinforcement for responding during $50 \%$ of the trials. When contact was made with a change in the reinforcement schedule, IRTs distributions changed.

The shape of the IRTs distributions also changed for 5 of the 10 subjects when the Cost condition was implemented. There was a decrease in the rate of responding during both Cost components for four AC subjects and one IN subject. Furthermore, responding ceased whenever a point was lost for two of the AC subjects. Only the behavior of the subjects who were earning points under both components of the Limited Hold schedule did not change with this transition. These results again support the contact explanation of Galizio (1979). The behavior of the subjects who were not earning reinforcers under both components of the Limited Hold condition was more likely to contact the Cost condition than the behavior of the subjects who were already earning points under both Limited Hold components. 
The differences in responding brought about by the Limited Hold and Cost conditions suggest that contact is necessary for behavior to change. The differences between groups on the number of points earned, however, indicated that contact is not sufficient to produce behavior that is reinforced under both components of the schedules. It appears that previous experience with the behavior reinforced under the test schedule may be necessary. Furthermore, data from the anomalous subjects suggest that even better control over behavior is necessary and that further investigations should be conducted.

\section{Future Research}

Certain issues related to the variability found both within and between groups should be addressed in future studies. As stated earlier, it is unclear why 4 of the 10 subjects' behavior changed with the transition from training to the Mixed DRL condition. One suggestion was that allowing IRTs between 8 and 10-s during training may have contributed to this sensitivity. This could be controlled by changing the stability criteria so that no IRTs $<10$-s can be emitted during the last three training blocks. Controlling for the possible effect of factors outside the experiment is a problem that is more difficult to circumvent. One possible solution might involve conducting the experiment in one long session. Subjects would be required to spend approximately 8 -hr in the laboratory with controlled breaks programmed every couple of hours.

Another issue that should be addressed involves the examination of the inaccurate instructions provided to the IN subjects. It may be argued that instructions specifying that short IRTs will be reinforced may result in short IRTs when extinction is contacted. Perhaps these effects would not have occurred for the IN subjects if they had received inaccurate instructions 
that asked them to respond at lower rates than the contingencies required. The effect of these particular instructions could be examined by presenting two different sets of inaccurate instructions. One inaccurately instructed group (IN long) could receive instructions that specify that reinforcers will be obtained by emitting IRTs that are longer than the schedule requirement, while another inaccurately instructed group (IN short) could receive instructions that specify that IRTs that are shorter than the schedule requirements will be reinforced. For example, a DRL 10-s Limited Hold 10-s schedule of reinforcement could be used as one of the training tasks. Whereas the accurately instructed subjects could be told to emit a response every 10 to 20 -s, the IN short subjects could be instructed to wait 2 -s between responses and the IN long group could be told to wait 28-s. If the behavior of both inaccurately instructed groups is sensitive to the differential availability of points, then it may be concluded more convincingly that the sensitivity of the IN subjects' behavior was due to their history of reinforcement for not following rules and not due to either the effect of the specific instructions or the effect of a history of high rate responding.

Another procedural change that could help examine how specifically historical variables affect sensitivity might involve shaping the appropriate responses for each task instead of accurately or inaccurately instructing subjects. If shaping leads to button pressing that also contacts the differential availability of points under both components of the mixed schedules, then the control of a specific inaccurate instruction would be disconfirmed. Under shaping conditions, however, it is likely that both high rates and low rates would occur and, therefore, the relation between high rate training performance and high rate test performance would still need to be investigated. 
To test the effect of the presentation of a variety of tasks during training, a study could be conducted where the number of training tasks is manipulated parametrically. If, for example, the current results are replicated although only the "Button" task is used during training, then it may be concluded that having a variety of tasks was not a necessary aspect of the current study's procedure. It should also be noted that the present experiment exclusively used female college students as subjects. Further empirical support for the conclusion that subjects' history of reinforcement for rule-following affects the sensitivity of their behavior could be obtained by systematically replicating the current experiment with subjects from different populations (e.g., male students and older individuals).

Additionally, a simple manipulation in any of the above studies could examine the effect of the order of component presentation on test performance. Some subjects could receive the 4-s component first and others could receive the 10-s component first to determine whether this order influences performance. Results from such a study might help explain why, out of all the IN subjects, only the behavior of the IN subject who received the 4-s Limited Hold and Cost components first did not contact the differential availability of points.

\section{$\underline{\text { Summary }}$}

The present study attempted to circumvent some of the problems other researchers have encountered when examining the effects of different histories of reinforcement for following rules on sensitivity to environmental changes. First, while other researchers have speculated about the effects that this type of history might have on sensitivity (e.g., Hayes et al., 1986) or have examined a correlated history (e.g., Wulfert et al., 1994), the present study directly 
manipulated rule-following histories. Second, a variety of tasks were used during training in an attempt to create an experimental history that would successfully override subjects' preexperimental history with following instructions. Previous studies have had difficulty obtaining behavior that was not controlled by the instructions (e.g., Ruckstuhl, 1996; ShamRao, 1994). Ruckstuhl (1996) suggested that a variety of tasks should be used because it would be more analogous to the types of situations encountered by people in natural settings where "sources" of information may be correct or incorrect about a variety of events. Third, mixed schedules that have led to differential sensitivity with changes in environmental contingencies (Lamons \& Chase, 1992) were used during testing. Furthermore, the manipulation of history was made between- subjects because of other researchers' difficulty in obtaining discriminative control when using a within-subjects procedure (e.g., Ruckstuhl, 1996).

The present study provides experimental evidence suggesting that subjects' history of reinforcement for not following rules is a factor that may increase behavior's sensitivity to changes in the environment. Although the present results do not isolate whether the specific history manipulated was responsible for the increased sensitivity, these results did suggest that the procedures appeared to be powerful enough to override subjects' pre-experimental history with instructions (cf., Hayes et al., 1986). The present experiment also supports previous findings that suggested the importance of contact with changes in the contingencies (Galizio, 1979). This study indicated, however, that contact was not sufficient and showed that different levels of contact with the changed contingencies leads to different levels of sensitivity (e.g., Lamons \& Chase, 1992). Furthermore, the present study suggests a relation between previous experience with the behavior that can be reinforced during contingency changes and sensitivity to these 
changes. This finding suggests the possibility that phenomena like resurgence (Epstein, 1985) may play a role in the sensitivity of behavior to changing conditions.

Based on the data presented here, it may be concluded that along with variables such as the variety of the instructions a subject has received (LeFrancois, Chase, \& Joyce, 1988), the variability present during the time of the contingency change (Joyce \& Chase, 1990), and the type of contact with the contingency changes (Galizio, 1979), subjects' history of reinforcement for rule-following will affect behavior's sensitivity to changes in the environment. These studies and the present experiment lend support to the notion that rule-governed behavior may be understood by the same principles discovered with basic operant experiments. For example, just as it has been shown that histories of reinforcement have strong effects on the behavior of nonhuman animals (e.g., Freeman \& Lattal, 1992), results from the present study suggest that a history of reinforcement for following or not following rules has strong effects on the sensitivity of rulegoverned behavior to changes in contingencies of reinforcement. 


\section{References}

Buskist, W. F., \& Miller, H. L. (1986). Interaction between rules and contingencies in the control of human fixed-interval performance. The Psychological Record, 36, 109-116.

Epstein, R. (1983). Resurgence of previously reinforced behavior during extinction. Behavior Analysis Letters, 3, 391-397.

Epstein, R. (1985). Extinction-induced resurgence: Preliminary investigations and possible applications. The Psychological Record, 35, 143-153.

Epstein, R., \& Skinner, B. F. (1980). Resurgence of responding after the cessation of responseindependent reinforcement. Proceedings of the National Academy of Sciences, U.S.A., 77, 6251-6253.

Freeman, T. J., \& Lattal, K. A. (1992). Stimulus control of behavioral history. Journal of the Experimental Analysis of Behavior, 57, 5-15.

Galizio, M. (1979). Contingency-shaped and rule-governed behavior: Instructional control of human loss avoidance. Journal of the Experimental Analysis of Behavior, 31, 53-70.

Hayes, S. C., Brownstein, A. J., Zettle, R. D., Rosenfarb, I., \& Korn, Z. (1986). Rule-governed behavior and sensitivity to changing consequences of responding. Journal of the Experimental Analysis of Behavior, 45, 237-256.

Joyce, J. H. \& Chase, P. N. (1990). Effects of response variability on the sensitivity of rulegoverned behavior. Journal of the Experimental Analysis of Behavior, 54, 251-262. 
Lamons, M. \& Chase, P. N. (1992). The effects of three kinds of contingencies on following rules. West Virginia Psychological Association, 1, 51-55.

LeFrancois, J. R., Chase, P. N., \& Joyce, J. H. (1988). The effects of a variety of instructions on human fixed-interval performance. Journal of the Experimental Analysis of Behavior, 49 . 383-393.

Madden, G. J., Chase, P. N., \& Joyce, J. H. (1998). Making sense of sensitivity in the human operant literature. The Behavior Analyst, 21, 1-12.

Rawson, R. A., Leitenberg, H., Mulick, J. A., \& Lefebvre, M. F. (1977). Recovery of extinction responding in rats following discontinuation of reinforcement of alternative behavior: A test of two explanations. Animal Learning and Behavior, 5, 415-420.

Ruckstuhl, K. E. (1996). The effects of a differential reinforcement and stimulus history for following rules on insensitivity to new contingencies. Unpublished doctoral dissertation, West Virginia University, Morgantown.

ShamRao, A. D. (1994). Schedule insensitivity as a function of a history of reinforcement and punishment for instruction-following. Unpublished doctoral dissertation, West Virginia University, Morgantown.

Shimoff, E., \& Catania, A. C. (1998). The verbal governance of behavior. In K. A. Lattal \& M. Perone (Eds.), Handbook of research methods in human operant behavior (pp. 371-404). New York: Plenum Press. 
Shimoff, E., Catania, A. C., \& Matthews, B. A. (1981). Uninstructed human responding: sensitivity of low-rate performance to schedule contingencies. Journal of the Experimental Analysis of Behavior, 36, 207-220.

Skinner, B. F. (1969). Contingencies of reinforcement: A theoretical analysis, New Jersey: Prentice-Hall.

Wilson, K. G., \& Hayes, S. C. (1996). Resurgence of derived stimulus relations. Journal of the Experimental Analysis of Behavior, 66, 267-281.

Wulfert, E., Greenway, D. E., Farkas, P., Hayes, S. C., \& Dougher, M. J. (1994). Correlation between self-reported rigidity and rule-governed insensitivity to operant contingencies. Journal of Applied Behavior Analysis, 27, 659-671. 
Appendix A

\section{CONSENT and INFORMATION FORM}

\section{TITLE OF RESEARCH: Effects of Instructions on Problem-Solving Tasks}

INTRODUCTION: I, , have been invited to participate in this research study which has been explained to me by either Dr. Philip N. Chase, Carolina Aguilera, or one of their assistants. This research is part of Carolina Aguilera's Master's thesis research, and may be partially funded by the Department of Psychology Alumni Fund and/or the Office of Academic Affairs.

PURPOSE OF THE STUDY: I understand that the purpose of this study is to learn more about how instructions facilitate problem-solving. I understand that data from my participation may be used to partially fulfill the requirements for a Master's thesis.

PROCEDURES: I understand that this project may require approximately 10 hours of my time. I understand that before each session, my watch will be requested of me if I am wearing one and that it will be kept in a safe location and returned to me immediately following each session.

I understand that I will participate in approximately one session per day and that during each session, I will be given some instructions to follow in order to earn points in various computer games. Each point that I earn will be exchangeable for money. I understand that if I complete the experiment, I will receive a $\$ 1.00$ bonus for every session I attend. The attendance bonus will be paid at the end of the experiment.

I understand that because of experimental protocol, it is important for me to come every day at my agreed upon time. I understand that if I miss a session, I will be asked to come in for a make-up session within a week of the missed session. I also understand that if I miss two or more sessions, or if I do not call in advance of missing a session, I may be dropped from the experiment. If I become ineligible to continue because of missed sessions, I understand that I will not receive the attendance bonus.

I understand that I will be paid at the end of the experiment and that the experimenters will keep careful track of my earnings. So that I may keep accurate records, they will also give me an earnings statement at the end of each session. 
I understand that I may be able to earn approximately $\$ 5.50$ per hour of participation, and that this amount includes both my performance earnings and my attendance bonus. I understand that I may be able to earn approximately $\$ 55.00$ for my performance during the experiment. There will be no monetary costs to me as a subject. Approximately 10 subjects will participate in this study.

RISKS AND DISCOMFORTS: I understand that there are no known or expected risks from participating in this study, except for the mild frustration associated with completing computer tasks. Furthermore, I am aware that there may be unforeseeable risks in participating in any experiment.

BENEFITS: I understand that this study will not necessarily be of direct benefit to me, but the knowledge gained may be of benefit to others. I understand that I will earn money based on my performance and attendance.

CONTACT PERSONS: For more information about this research, I can contact Dr. Philip N. Chase at 293-2001, ext. 626, or Carolina Aguilera at 293-2001, ext. 822. For more information regarding my rights as a subject, I may contact the Executive Secretary of the Institutional Review Board at (304) 293-7073.

CONFIDENTIALITY: I understand that any information about me obtained as a result of my participation in this research will be kept as confidential as legally possible. I understand also that my research records, just like hospital records, may be subpoenaed by court order or may be inspected by federal regulatory authorities. In any publications that result from this research, neither my name nor any information from which I might be identified will be published.

VOLUNTARY PARTICIPATION. Participation in this study is voluntary. I understand that I am free to withdraw my consent to participate in this study at any time. Refusal to participate or withdrawal will involve no penalty or loss of benefits and will not affect my grades or class standing. I have been given the opportunity to ask questions about the research, and I have received answers concerning areas I did not understand.

Upon signing this form, I will receive a copy.

I willingly consent to participate in this study.

Signature of Subject or Subject's Representative

Date Time

Signature of Investigator or Investigator's Representative

Date

Time 


\section{Appendix B}

This is the room where the sessions will be conducted [experimenter takes subject to room]. Please have a seat [experimenter points to chair]. This computer [pointing to the computer] will run the experimental session. Instructions on what you need to do to earn points will be presented on the screen. What you see right now is the first screen of a set of general instructions that will tell you the same information I am telling you now. You will press a button labeled "Continue" to page through the first three screens which contain general information. After the third screen is presented, you will be prompted to press "Continue" to start the session. You will then get a screen with instructions on how to play the first game. Read these instructions carefully and when you are ready to begin the first game, press on the "Start" button. You will then be presented with the first game. After 6 minutes, you will get a message telling you to press "OK" to continue to a new game. After the end of the fourth game, the computer will tell you to call the experimenter. You have to come out and get me because I won't know when you have finished playing the games. You will then have a 5 minute break. After the break, you will get to continue playing the games. After you finish playing the games a second time, the computer will once again tell you to come get me. Please do so.

Pay close attention to the instructions before each game. They will tell you how you might earn points. When you have followed the game instructions correctly, you will hear a beep. Every time this happens, a button labeled "Register" will appear on the screen. You have to register your point by pressing this button. When you register a point, you will hear another beep, see a stack of coins appear briefly on the screen, and you will also see the point counter on your screen increment by one. It is important that you always register your points when you earn them since you cannot 
earn more points until you register your last point. During each game, a point counter will tell you how many points you have earned in that game.

Sometimes it takes people a little while to get the hang of new things. Please be patient if you do not start earning points right away. The computer is not broken and there is nothing wrong with you either. It's just that sometimes it takes a while to get used to what you need to do to earn points. Please remember to keep trying to earn as many points as possible throughout the whole experiment. 
Appendix C

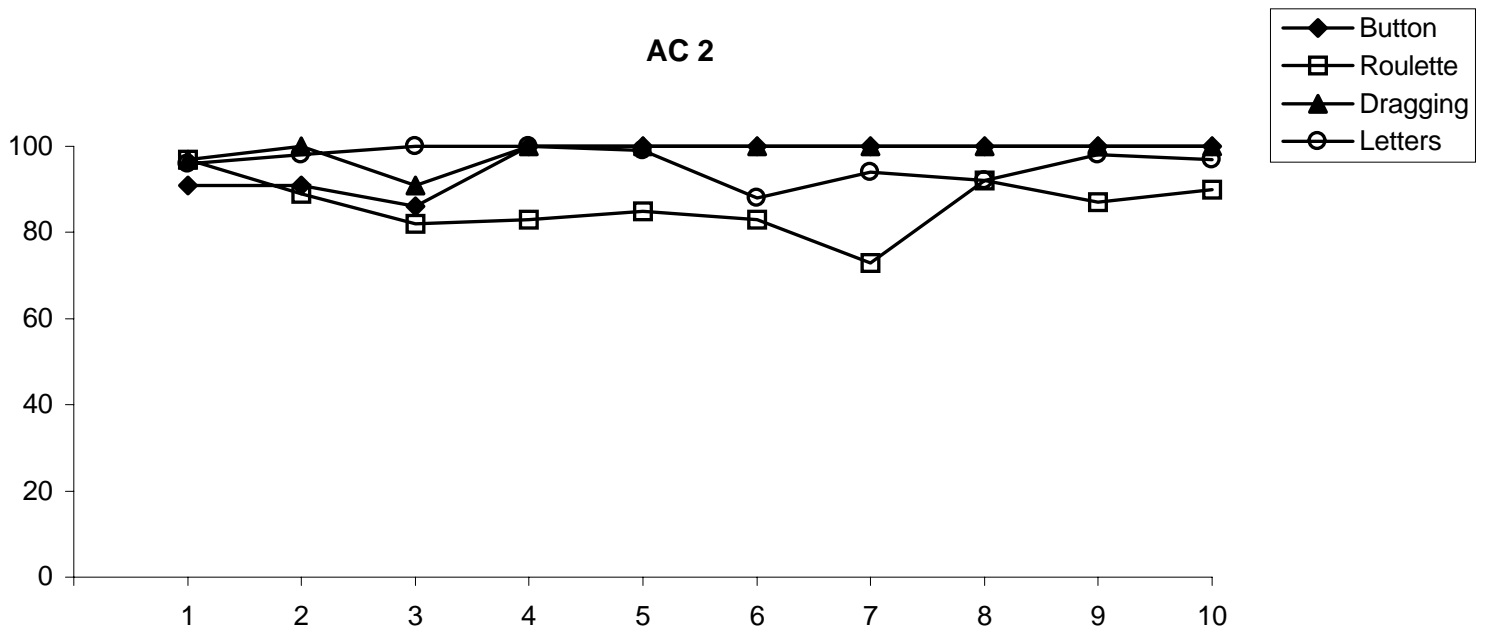

AC 3

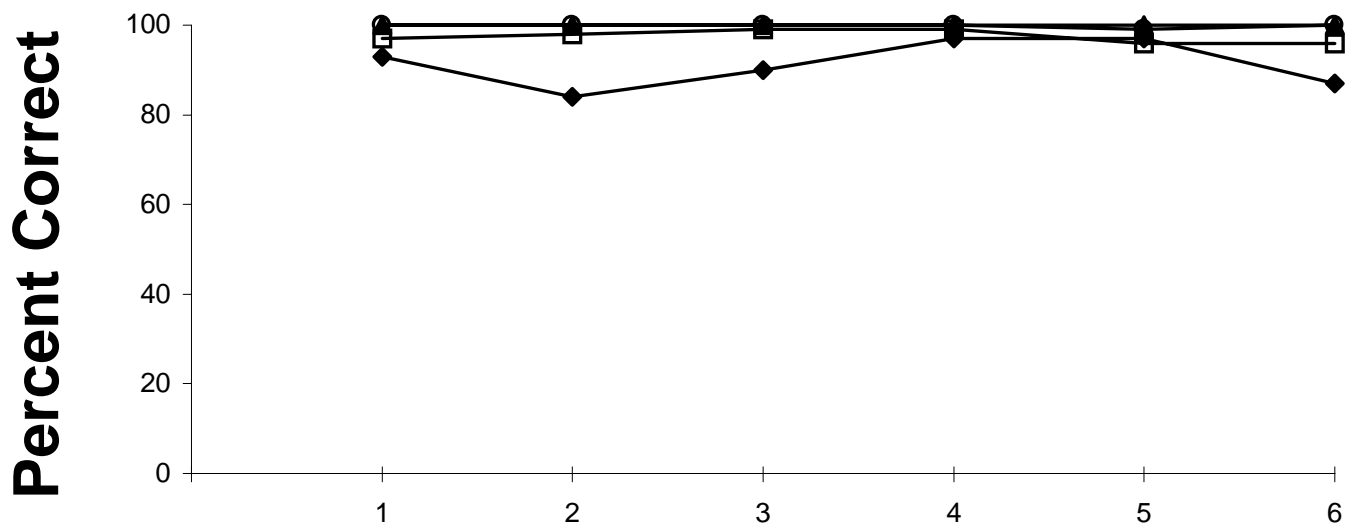

AC 4

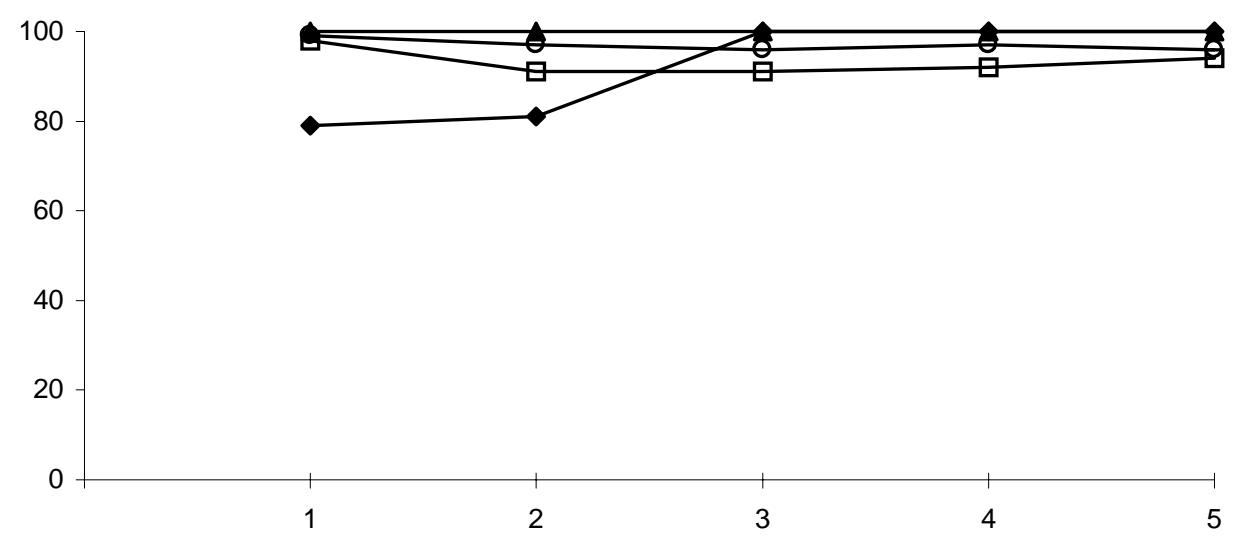

Block of Trials 


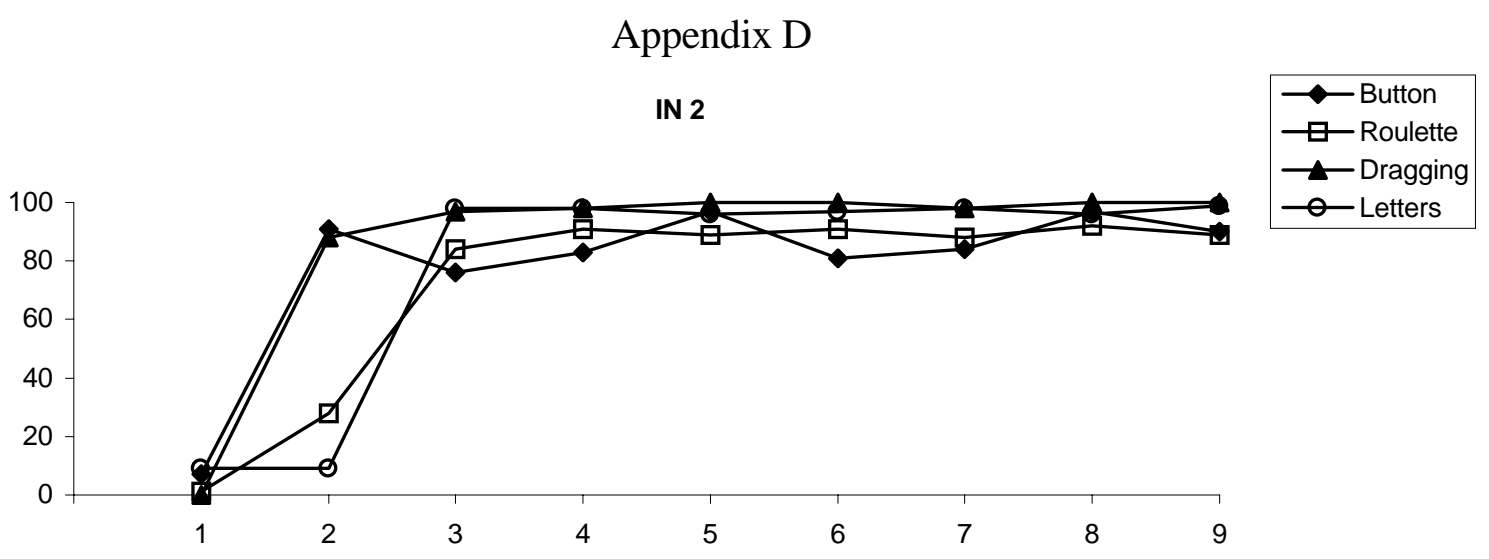

IN 3

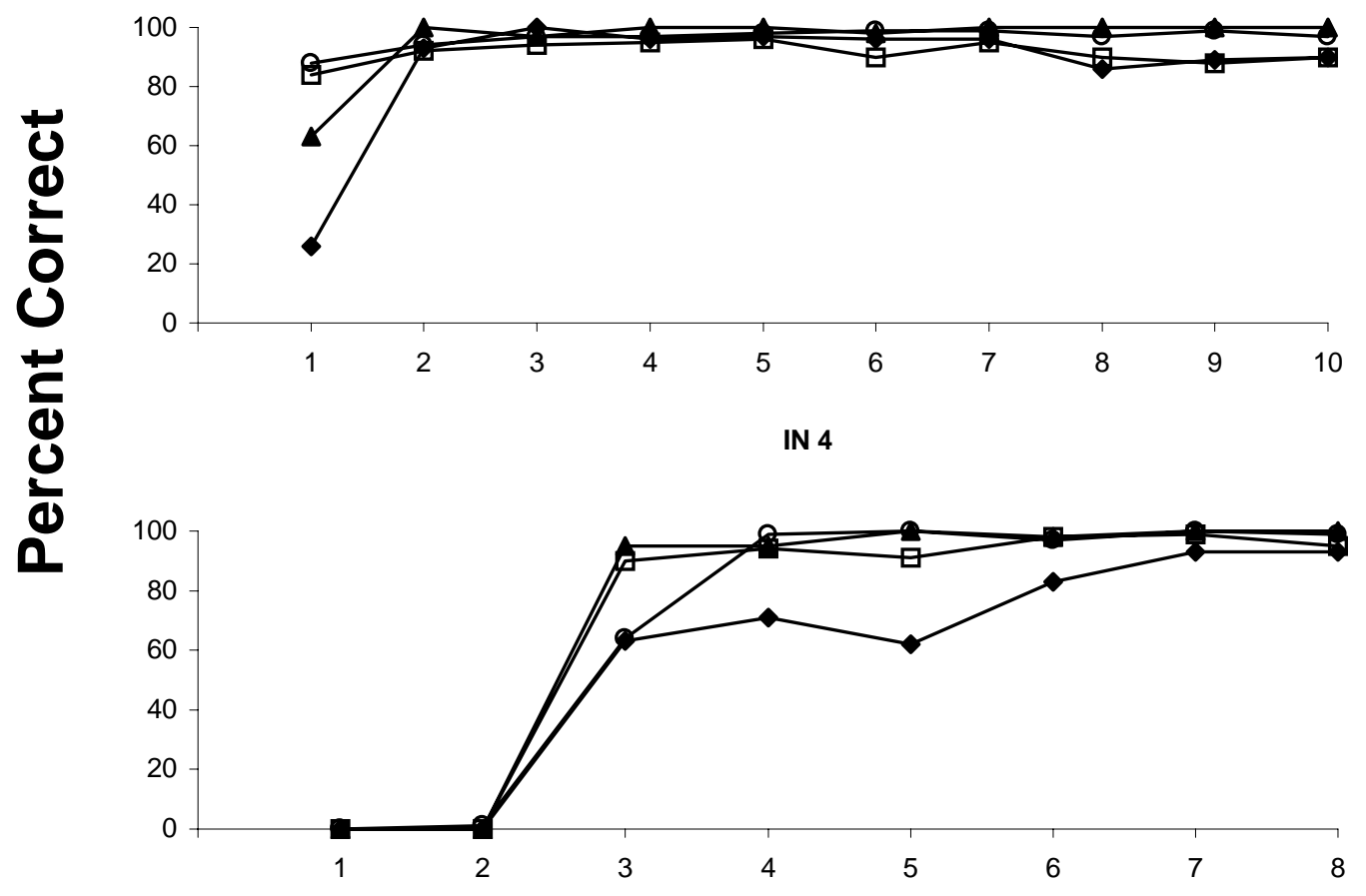

IN 5

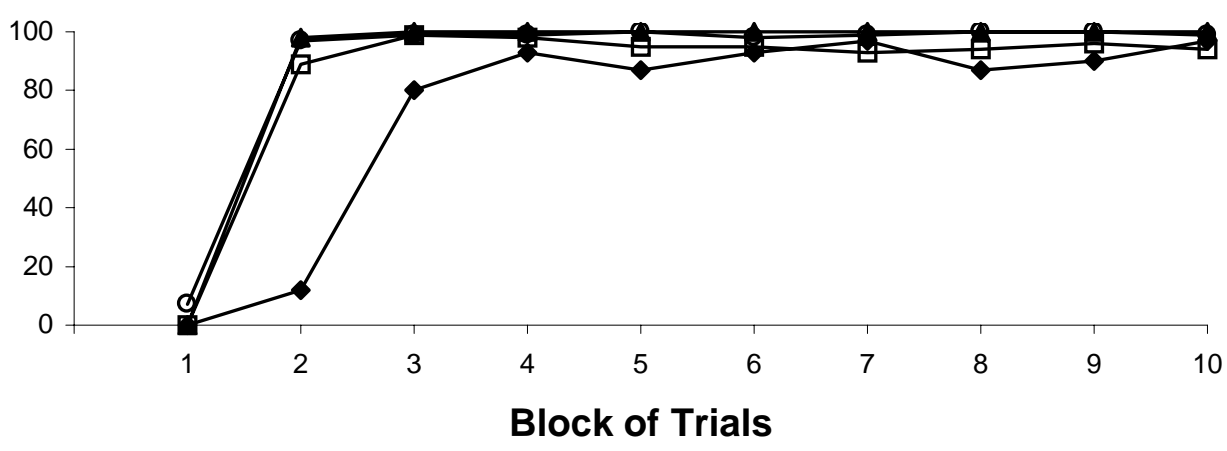


Appendix E

\section{AC 2}

$\rightarrow$-Training
- $-10-\mathrm{s}$
$-\mathbf{0}-4-\mathrm{s}$

Training

Mixed DRL

Limited Hold

Cost

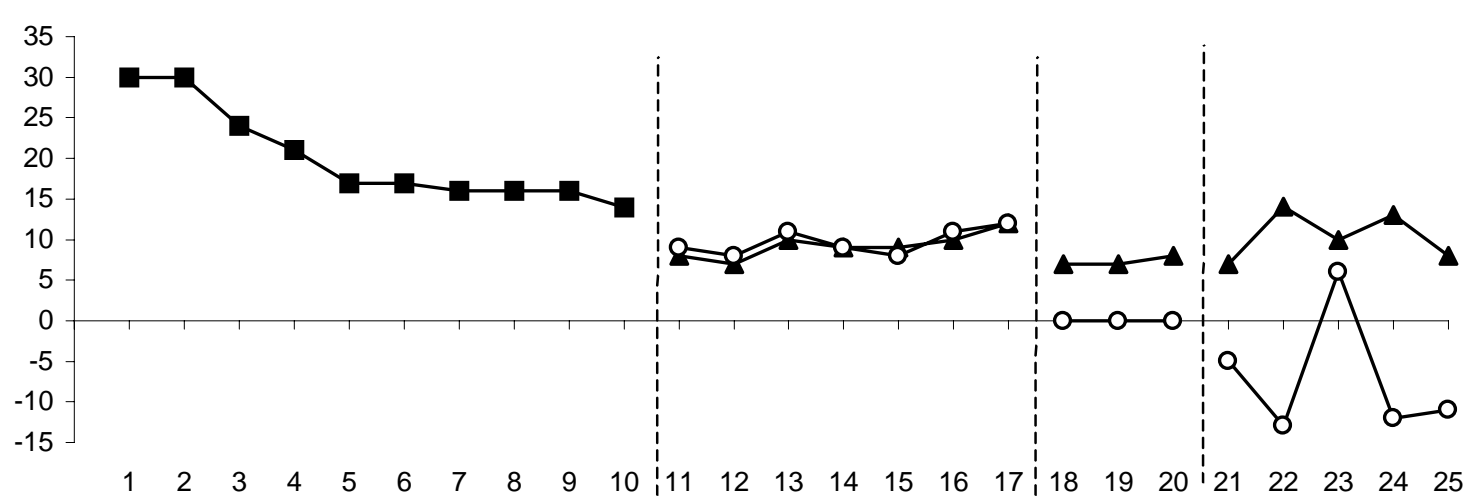

AC 3

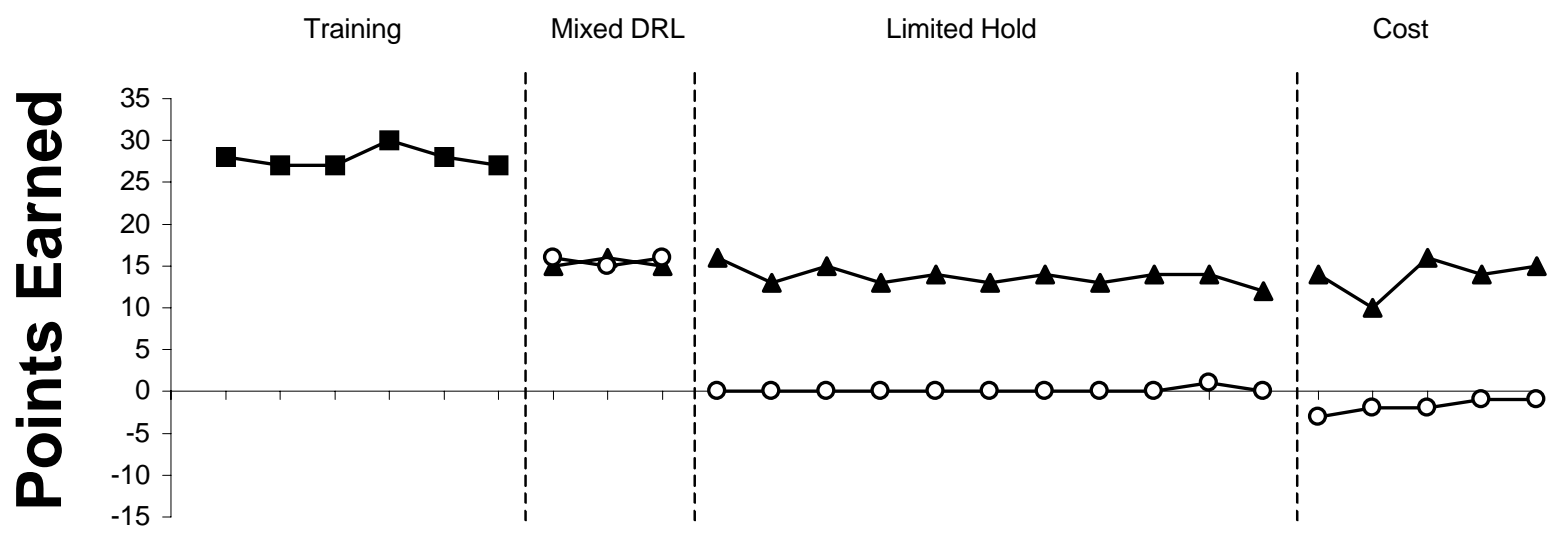

$\begin{array}{lllllllllllllllllllllllll}1 & 2 & 3 & 4 & 5 & 6 & 7 & 8 & 9 & 10 & 11 & 12 & 13 & 14 & 15 & 16 & 17 & 18 & 19 & 20 & 21 & 22 & 23 & 24 & 25\end{array}$

AC 4

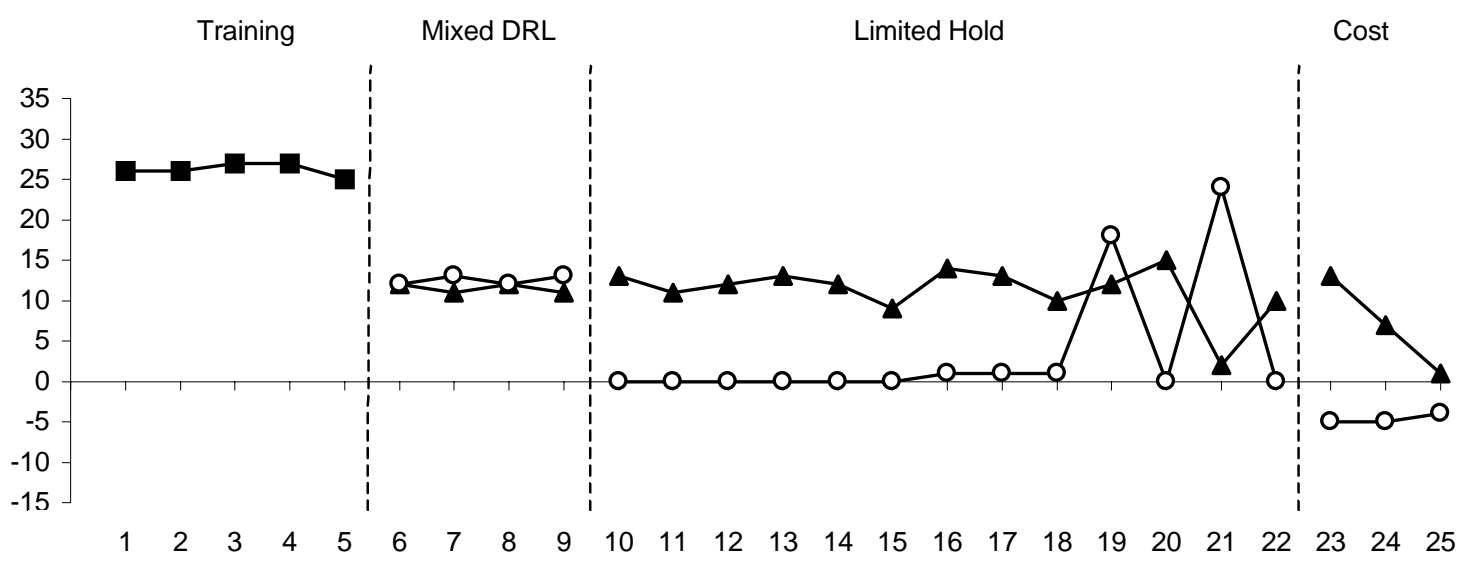

\section{Block of Trials}




\section{Appendix F}

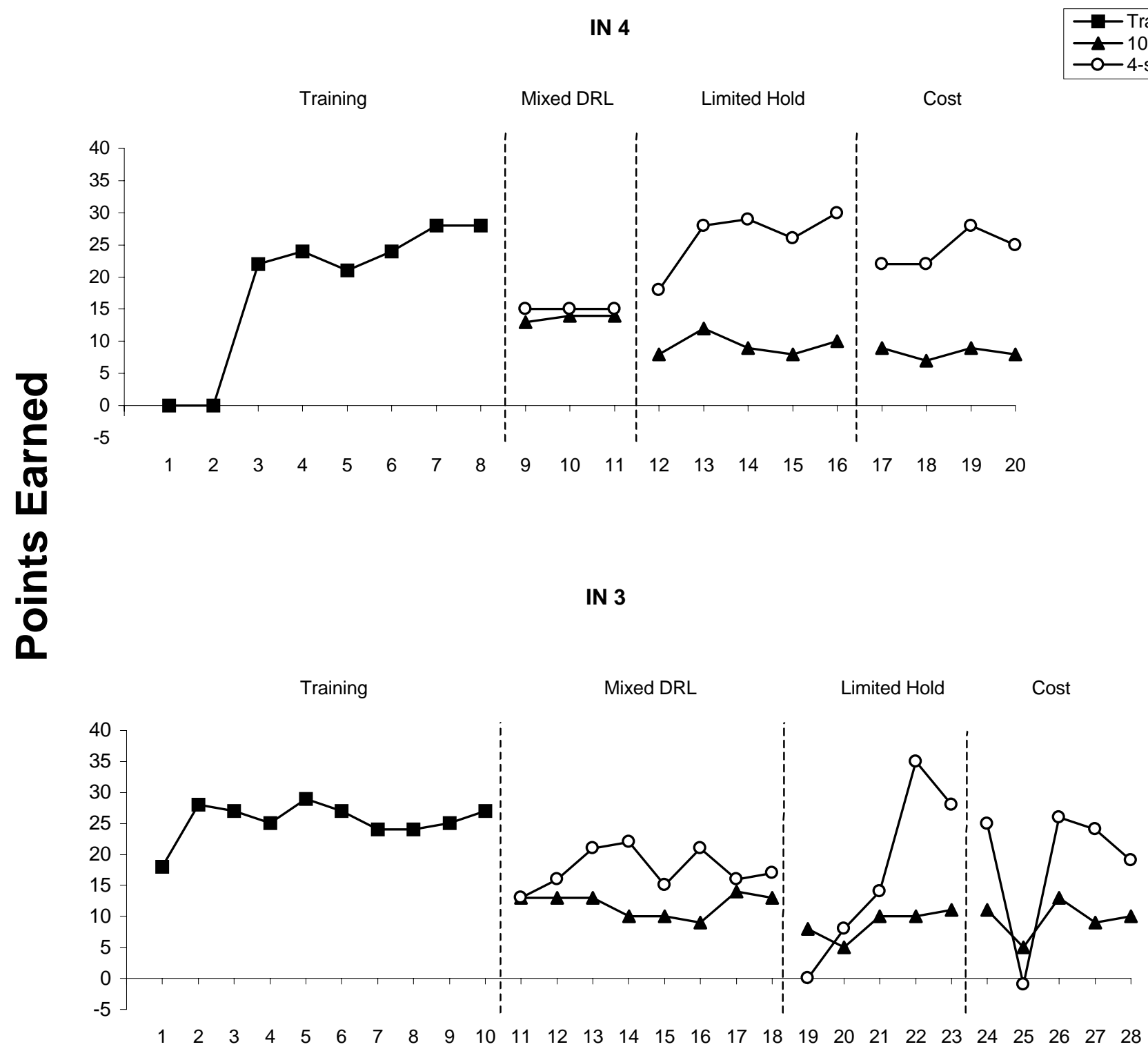

\section{Block of Trials}

